\title{
Combinatorial Expression of Brn3 Transcription Factors in Somatosensory Neurons: Genetic and Morphologic Analysis
}

\author{
Tudor Constantin Badea, ${ }^{1,5}$ John Williams, ${ }^{1,4}$ Philip Smallwood, ${ }^{1,4}$ Melody Shi, ${ }^{5}$ Oluwaseyi Motajo, ${ }^{5}$ \\ and Jeremy Nathans $\mathbf{s}^{1,2,3,4}$ \\ Departments of ${ }^{1}$ Molecular Biology and Genetics, ${ }^{2}$ Neuroscience, and ${ }^{3}$ Ophthalmology, and the ${ }^{4}$ Howard Hughes Medical Institute, Johns Hopkins \\ University School of Medicine, Baltimore, Maryland 21205, and ${ }^{5}$ National Eye Institute, NIH, Bethesda, Maryland 20892
}

The three members of the Brn3 family of POU-domain transcription factors (Brn3a/Pou4f1, Brn3b/Pou4f2, and Brn3c/Pou4f3) are expressed in overlapping subsets of visual, auditory/vestibular, and somatosensory neurons. Using unmarked Brn3-null alleles and Brn3 conditional alleles in which gene loss is coupled to expression of an alkaline phosphatase reporter, together with sparse Cre-mediated recombination, we describe the following: (1) the overlapping patterns of Brn3 gene expression in somatosensory neurons; (2) the manner in which these patterns correlate with molecular markers, peripheral afferent arbor morphologies, and dorsal horn projections; and (3) the consequences for these neurons of deleting individual Brn3 genes in the mouse. We observe broad expression of $B r n 3 a$ among DRG neurons, but subtype-restricted expression of $B r n 3 b$ and $B r n 3 c$. We also observe a nearly complete loss of hair follicle-associated sensory endings among $\mathrm{Brn}_{3} \mathrm{a}^{-1-}$ neurons. Together with earlier analyses of $\mathrm{Brn} 3$ gene expression patterns in the retina and inner ear, these experiments suggest a deep functional similarity among primary somatosensory neurons, spiral and vestibular ganglion neurons, and retinal ganglion cells. This work also demonstrates the utility of sparse genetically directed labeling for visualizing individual somatosensory afferent arbors and for defining cell-autonomous mutant phenotypes.

\section{Introduction}

Primary somatosensory neurons convey information from the skin and body interior about temperature, mechanical stimulation, tissue damage, and joint and muscle position (Lumpkin and Caterina, 2007; Basbaum et al., 2009; Proske and Gandevia, 2009). The diversity of somatosensation is mirrored in the diversity of peripheral nerve endings, which vary in complexity from free nociceptive endings in the skin to intricate structures such as Pacinian corpuscles and muscle spindles. Diversity is also seen in nerve conduction velocity and its anatomic counterparts, axon diameter and myelination. In the dorsal horn of the spinal cord, the central projections of the primary somatosensory neurons are organized in laminae, with distinct subtypes of somatosensory fibers projecting to only one or a few laminae (Sanderson Nydahl et al., 2004; Zylka et al., 2005; Bourane et al., 2009; Luo et al., 2009).

A growing collection of molecular markers and gene knockout mouse lines has facilitated the identification and characterization of different subtypes of somatosensory neurons. The

\footnotetext{
Received Sept. 17, 2011; accepted Nov. 17, 2011.

Author contributions: T.C.B. and J.N. designed research;T.C.B., J.W.,P.S., M.S., 0.M., and J.N. performed research; T.C.B., M.S., O.M., and J.N. analyzed data; T.C.B. and J.N. wrote the paper.

This work was supported by the Howard Hughes Medical Institute and the National Institutes of Health. We thank Rocky Cheung, Sumit Kumar, and Yanshu Wang for help with histology and immunostaining; and Xinzhong Dong, David Ginty, Qin Liu, and Ting Guo for helpful discussions and/or comments on this manuscript.

Correspondence should be addressed to either of the following: Dr. Tudor Constantin Badea, Building 6, National Eye Institute, NIH, Bethesda, MD 20892, E-mail: badeatc@mail.nih.gov; or Dr. Jeremy Nathans, 805 PCTB, 725 North Wolfe Street, Johns Hopkins University School of Medicine, Baltimore, MD 21205, E-mail: jnathans@jhmi.edu.

T. C. Badea's present address: National Eye Institute, NIH, Bethesda, Maryland 20892.

DOI:10.1523/JNEUROSCI.4755-11.2012

Copyright $\odot 2012$ the authors $\quad 0270-6474 / 12 / 320995-13 \$ 15.00 / 0$
}

markers include TRPV (transient receptor potential vanilloid) channels, Mas-related G-protein-coupled receptors (Mrgprs), cytosolic proteins such as parvalbumin and neurofilament-200 (NF-200), and neuropeptides such as calcitonin gene-related peptide (CGRP) (Fundin et al., 1997a; Tominaga et al., 1998; Zylka et al., 2005; Liu et al., 2009; Luo et al., 2009). Of special interest are genes and proteins that control the development and diversification of somatosensory neurons-in particular, the neurotrophic factor receptors RET, Trk, and GFR- $\alpha$ (glial cell line-derived neurotrophic factor- $\alpha$ ), and the transcription factors Sox 10, Neurogenin-2, Islet-1, MafA, and the members of the Runx and Brn3 families (Eng et al., 2007; Marmigère and Ernfors, 2007; Inoue et al., 2008; Sun et al., 2008; Bourane et al., 2009; Lanier et al., 2009; Dykes et al., 2010). Sox10 controls the proliferation of neural progenitors in the DRG and TG, and Islet- 1 and Brn3a control, directly or indirectly, the expression of a large number of genes in DRG and TG neurons, including Runx genes. The TrkA and TrkC neurotrophin receptors, which are controlled in part by Runx1 and Runx3, play critical roles in the differentiation and survival of nociceptors, mechanoreceptors, and proprioreceptors.

The present work focuses on the three members of the Brn3 family of transcription factors: Brn3a/Pou4f1, Brn3b/Pou4f2, and Brn3c/Pou4f3. Each Brn3 gene is expressed in distinct sets of neurons in each of three sensory organs-the retina, inner ear, and DRG/TG. We have recently developed $B r n 3 a, B r n 3 b$, and Brn3c conditional knock-out/alkaline phosphatase (AP) knock-in mouse lines that permit a genetic and morphologic analysis of individual neurons (Badea et al., 2009a; present work). We report here the use of these lines to define-for both WT and 
Brn3 mutant mice-the overlapping patterns of Brn3 gene expression among DRG neurons, the morphologies of their afferent arbors, and their central target fields in the dorsal horn of the spinal cord. The results imply that the Brn3 proteins contribute to sensory neuron diversity by participating in a combinatorial code of transcriptional regulation and that there are deep functional similarities in transcriptional circuits across diverse sensory systems.

\section{Materials and Methods}

Mouse lines. The following lines were previously described: (1) Cre lines: Sox2Cre (Hayashi et al., 2002), Pax6 $\alpha$ Cre (Marquardt et al., 2001), ROSA26CreER (Badea et al., 2003), NFL-CreER (Rotolo et al., 2008), and R26rtTACreER (Badea et al., 2009b); (2) conventional knock-out lines: Brn3a (Xiang et al., 1996) Brn3b (Gan et al., 1996) and Brn3c (Xiang et al., 1997); and (3) conditional knock-in alleles: $B r n 3 a^{C K O A P}$ and $B r n 3 b^{C K O A P}$ (Badea et al., 2009a). The Brn3c ${ }^{C K O A P}$ conditional allele was generated by homologous recombination in mouse embryonic stem cells using standard techniques. For the targeted allele, the following changes were made: a loxP site was inserted in the $5^{\prime}$ UTR 50 bp $5^{\prime}$ before the initiator ATG; three repeats of the SV40 early region transcription terminator were added to the 3' UTR $600 \mathrm{bp} \mathrm{3'}$ of the Brn3c translation termination codon, followed by a second loxP site and the coding region of human placental AP. A positive selection cassette Phosphoglycerate-KinaseNeomycin Resistance gene (PGK-Neo), flanked by frt sites, followed the AP coding region, and was subsequently removed by crossing to mice expressing Flp recombinase in the germline, as previously described (Badea et al., 2009a).

Sparse recombination. For methods related to sparse Cre-mediated recombination, see Badea et al. (2003), Rotolo et al. (2008), Badea et al. (2009b), and Badea and Nathans (2011). For each of the three Brn3 genes, timed matings between $\mathrm{Brn}^{+/-} ; R 26^{r t T A C r e E R /+}$ males and $B r n 3^{C K O A P / C K O A P}$ females were set, conception date was determined by examining the copulation plug, and pregnant females were moved to cages with food pellets containing doxycyline $(1.75 \mathrm{mg} / \mathrm{g})$ at gestational day 3. At gestational day 9, $200 \mu \mathrm{g}$ of 4-hydroxytamoxifen (4HT) in sunflower seed oil vehicle was delivered by intraperitoneal injection, and the doxycycline diet was continued until gestational day 11. P1-P4 pups were used for skin AP histochemistry (see Figs. 5, 6, 7), whereas adults were used for spinal cord AP histochemistry (see Fig. 7). For visualizing somatosensory afferents in $\mathrm{Brn}_{3}{ }^{\mathrm{CKOAP} /{ }^{+}} ; \mathrm{NFL}-\mathrm{CreER}$ mice (see Fig. 5), females were injected intraperitoneally with $0-200 \mu \mathrm{g}$ of $4 \mathrm{HT}$ at gestational day $14-17$, and mice were analyzed at P1-P3. DRG immunostain-

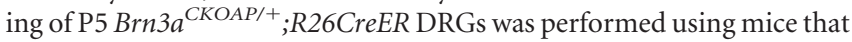
were not exposed to $4 \mathrm{HT}$, taking advantage of the background rate of Cre-mediated recombination in the absence of $4 \mathrm{HT}$.

Histology. Spinal cord and brain vibratome sections (typically $200 \mu \mathrm{m}$ thickness) were fixed, AP stained, processed, and imaged as previously described (Badea et al., 2003, 2009a). For vibratome sections of early postnatal pups, eviscerated torsos were fixed overnight in $\mathrm{PBS} / 4 \%$ paraformaldehyde at $4^{\circ} \mathrm{C}$, and then decalcified for $\sim 4 \mathrm{~d}$ in $50 \mathrm{~mm}$ EDTA at $4^{\circ} \mathrm{C}$. Skin flatmounts were prepared by pinning dissected skin (external surface downward) to a Sylguard surface with insect pins and fixing overnight in $\mathrm{PBS} / 4 \%$ paraformaldehyde at $4^{\circ} \mathrm{C}$. Retina sections were processed and immunostained as previously described (Badea et al., 2009a). For spinal cord and DRG immunostaining, adult or early postnatal mice were perfused intracardially with $\mathrm{PBS} / 4 \%$ paraformaldehyde, and the vertebral column was dissected, decalcified, cryoprotected in Optimal Cutting Temperature Compound (Tissue-Tek-Sakura), and sectioned at $14 \mu \mathrm{m}$ thickness on a cryostat. Complete spinal cords with attached DRGs from two to four mice of the same genotype were cut transversely into 4 segments of equal length, and these 8-16 segments were embedded together in a single block. For each immunostaining analysis cells were counted from six to eight sections at cervical, thoracic, and lumbar levels. No significant differences in patterns of dorsal horn lamination or the frequency of Brn3a-, Brn3b-, or Brn3c-expressing DRG neurons were noted across spinal cord levels with the markers used in this study. High-resolution images were captured on a Zeiss Imager.Z1 fitted with an Apotome for fluorescent imaging and Axiovision software. Skin afferent neurons were imaged with a black-and-white Axiocam camera using differential interference contrast/Nomarsky optics, and neuronal arbors were reconstructed using Neuromantic neuronal tracing freeware (Darren Myat, http:// www.reading.ac.uk/neuromantic) and were exported to the Rotator visualization software using scripts written in Matlab (Mathworks).

Antibodies. Rabbit polyclonal anti-Brn3a, anti-Brn3b, and anti-Brn3c antisera are described in Xiang et al. (1995). For double immunostaining with rabbit antibodies to Brn3 proteins and cytoplasmic markers, the anti-Brn3 immunostaining was performed first, the patterns of nuclear immunolabeling were captured, and then the anti-cytoplasmic marker immunostaining was performed and the labeling pattern compared with the earlier image. The sources of commercial antibodies are as follows: sheep anti-AP (American Research Products); rabbit anti-Neurofilament 200, anti-Peripherin, and anti-TrkA, and mouse monoclonal anti-Brn3a (MAB1585; Millipore); rabbit anti-parvalbumin (Swant); guinea pig anti-CGRP (Bachem); rabbit anti-PKC $\gamma$ (Santa Cruz Biotechnology). Secondary antibodies were donkey antisera coupled with Alexa dyes (Invitrogen/Life Technologies). Isolectin B 4 (IB4) conjugates were from Invitrogen/Life Technologies.

\section{Results \\ Central projections of Brn3c-expressing RGCs visualized by expression of alkaline phosphatase from the $\mathrm{Brn} 3 \mathrm{c}$ locus}

To eliminate $B r n 3 c$ function via Cre-mediated recombination and to simultaneously visualize individual neurons expressing the recombined $B r n 3 c$ allele, one loxP site was inserted in the $B r n 3 c 5^{\prime}$ UTR, a second loxP site was inserted 3' of the Brn3c transcription termination signal, and an AP reporter coding region was inserted distal to the $3^{\prime}$ loxP site (Fig. 1A). Expression of the AP reporter is activated by Cre-mediated deletion of the $B r n 3 c$ coding region and $3^{\prime}$ UTR, bringing AP under the control of the Brn3c promoter. The same "conditional knockout with AP" (CKOAP) strategy was previously applied to the $B r n 3 a$ and $B r n 3 b$ genes (Badea et al., 2009a). When the conditional allele is placed over a WT allele $\left(B r n 3 c^{C K O A P /+}\right)$, Cre-mediated recombination generates phenotypically normal $B r n 3 c^{A P /+}$ cells. When the conditional allele is placed over a conventional null allele $\left(B r n 3 c^{C K O A P /-}\right)$ (Xiang et al., 1997), Cre-mediated recombination generates phenotypically mutant $B r n 3 c^{A P /-}$ cells. In both cases, the AP reporter permits histochemical and immunocytochemical visualization of cell bodies and arbor morphologies. Figure $1 B$ shows the colocalization of nuclear Brn3c and plasma membrane-anchored AP in Brn3 $c^{A P /+}$ RGCs (Fig. $1 B$, top), and the loss of Brn3c protein with the retention of AP expression in $B r n 3 c^{A P /-}$ RGCs (Fig. $1 B$, bottom).

In earlier work, we used $B r n 3 a^{C K O A P}$ and $B r n 3 b^{C K O A P}$ alleles to determine the central projections of RGCs expressing these two genes. A similar analysis with $B r n 3 c^{C K O A P}$, using the retinaspecific Pax6 $\alpha$ Cre transgene (Marquardt et al., 2001), shows projections to the lateral geniculate nucleus and superior colliculus (Fig. $1 C f-j, l$ ). In contrast to Brn3a- and Brn3b-expressing RGCs, $B r n 3 c$-expressing RGCs do not project to the medial terminal nucleus nor do they contribute to the lateral terminal tract, both of which are involved in eye movement control as part of the accessory optic tract (Fig. $1 C$, compare $a-e, f-j$ ). Also in contrast to Brn3b-expressing RGCs, Brn3c-expressing RGCs bypass the suprachiasmatic nucleus (SCN) (Fig. 1Ck). An analysis of the dendritic morphologies of both $B r n 3 c^{A P /+}$ and $B r n 3 c^{A P /-}$ RGCs is reported in Badea and Nathans (2011); loss of Brn3c appears to have little or no effect on the survival or morphology of these RGCs (see also Wang et al., 2002). 

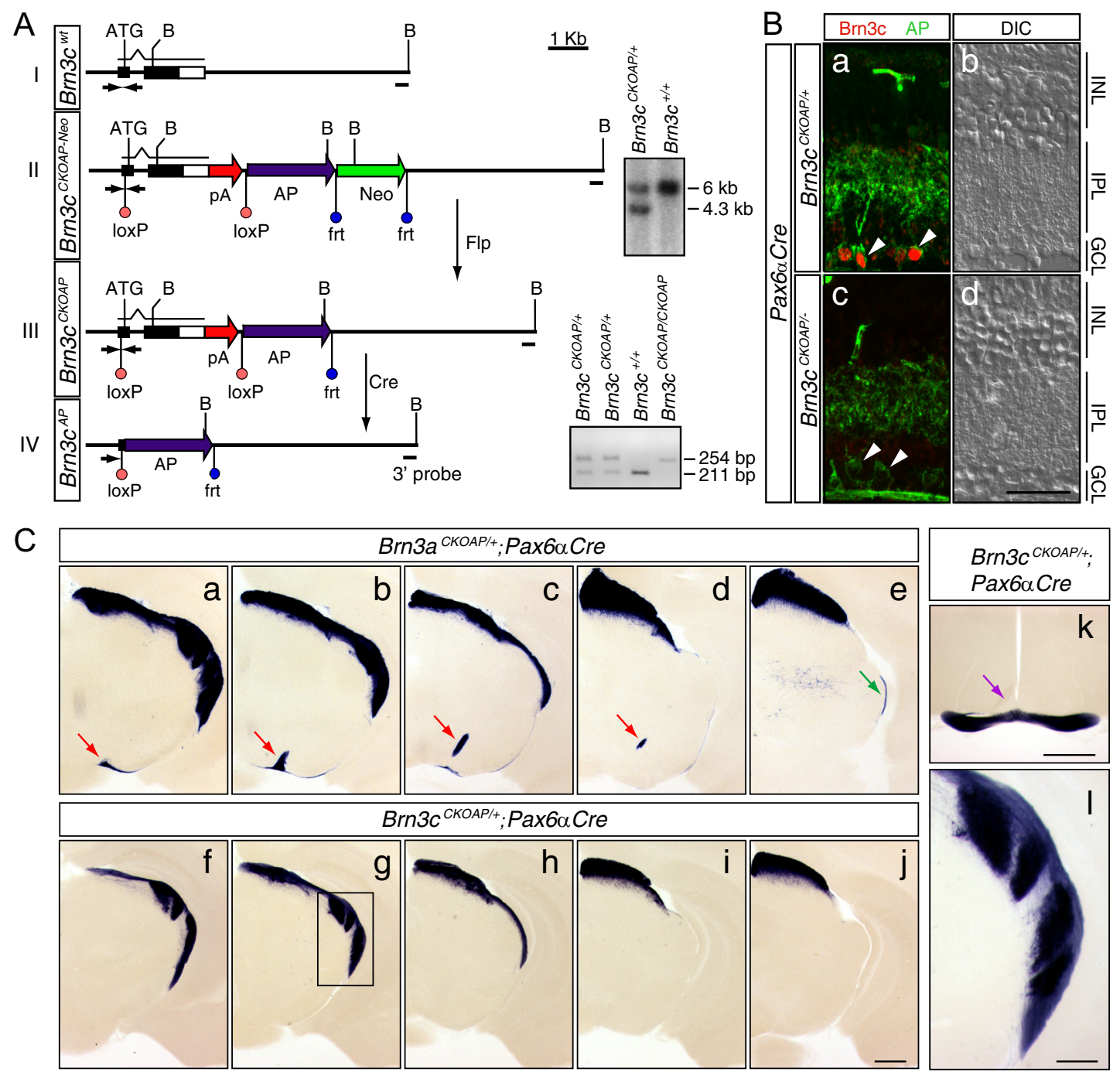

Figure 1. Conditional Brn3c allele with an AP reporter reveals central targets of Brn3c-expressing RGCs. A, Gene targeting strategy. I, WT Brn3c gene; II, targeted Brn3c gene with a PGK-Neo cassette flanked by frt sites; III, $B r n 3 C^{C K O A P}$ allele with the Neo cassette excised by germline Flp recombination; and IV, Brn3 $C^{A P}$ allele following Cre-mediated deletion of the Brn3c coding region. Filled black rectangles, 5' UTR and coding region; open rectangle, 3' UTR; red arrow labeled "pA," additional polyadenylation sites added to the 3' UTR; ATG, initiator methionine codon; AP, AP coding region and 3' UTR. The line above the gene indicates the structure of the spliced Brn3ctranscript. B, BamHI. The bar labeled "3' probe" indicates the location of the Southern blot hybridization probe. Arrows flanking the $5^{\prime}$ loxP site show the locations of PCR primers. Right, Genotyping by Southern blot (top) and PCR (bottom). B, Cre-mediated deletion of the Brn3c coding region in Brn3 $C^{C K O A P /+}$ or Brn3 $C^{C K O A P /-}$ retinas by Pax6 $\alpha$ Cre activates AP expression in a subset of RGCs and simultaneously eliminates Brn3c protein from RGCs in Brn $3 C^{\text {CKOAP/- }}$ retinas as determined by immunostaining of adult retinas with anti-AP (green; plasma membrane) and anti-Brn3c (red; nuclei) antibodies. White arrowheads point to AP+ RGC somas; green fluorescent anti-mouse secondary antibodies also decorate intraretinal capillaries. INL, Inner nuclear layer; IPL, inner plexiform layer; GCL, ganglion cell layer. C, Central projections of Brn3a-versus Brn3c-expressing RGCs in coronal sections of adult brain histochemically stained for AP (purple). Retina-specific Cre-mediated recombination is conferred by Pax6 $\alpha$ Cre. Matched pairs of serial sections (e.g., $\boldsymbol{a}$ and $\boldsymbol{f}, \boldsymbol{b}$ and $\boldsymbol{g}$ ) proceed from anterior at the mid-LGN $(\boldsymbol{a}, \boldsymbol{f}$; approximately bregma -2.5$)$ to posterior at the anterior colliculus $(\boldsymbol{e}, j$; approximately bregma -3.5$)$. Brn3a $a^{A P /+} \operatorname{RGC}$ axons $(\boldsymbol{a}-\boldsymbol{e})$. Red arrows, medial terminal tract and nucleus; green arrow, lateral aspect of the accessory optic tract. $B r n 3{ }^{A P /+} \operatorname{RGC}$ axons $(\boldsymbol{f}-\boldsymbol{I}) \cdot \boldsymbol{k}$, The optic chiasm and optic tracts (bottom) are populated by $B r n 3 c$-expressing RGC axons, but the SCN (purple arrow) is not targeted by axons of Brn3c-expressing RGCs. $\boldsymbol{l}$, The boxed LGN region in $\boldsymbol{g}$ is enlarged; the intergeniculate leaflet is seen as a central unstained region. Scale bars: $\boldsymbol{B}, 40 \mu \mathrm{m}$; Ca-j, $500 \mu \mathrm{m} ; C_{k}, 500 \mu \mathrm{m} ; \mathrm{Cl}, 200 \mu \mathrm{m}$.

The effect of mutations in each Brn3 gene on the expression of other Brn3 family members in RGCs

A high degree of functional similarity among the members of the Brn3 family is suggested by the following: (1) the near identity of the DNA binding domains of Brn3a, Brn3b, and Brn3c; (2) the ability of the Brn3a coding region to substitute for the Brn3b coding region to permit RGC survival (Pan et al., 2005); and (3) the partial redundancy of Brn3b and Brn3c in mediating RGC survival and intraretinal axon guidance (Wang et al., 2002). The extensive overlap in Brn3a, Brn3b, and Brn3c expression in RGCs (Xiang et al., 1995; Badea et al., 2009a) and the evidence that Brn3a negatively regulates its own transcription in DRG neurons (Trieu et al., 2003) led us to ask whether there might be cross- regulation among Brn3 family members in those neurons in which two or more Brn3 genes are expressed. As an initial test of this idea, we have immunolocalized each Brn3 protein together with AP in RGCs of genotypes $B r n 3 a^{A P /+}, B r n 3 a^{A P /-}, B r n 3 b^{A P /+}$, $B r n 3 b^{A P /-}, B r n 3 c^{A P /+}$, and $B r n 3 c^{A P /-}$. For this analysis, the Pax $6 \alpha C$ re transgene was used to generate retina-specific Cremediated recombination at $\sim$ E9.5 (Marquardt et al., 2001). For the Brn3-null mutant cells (i.e., Brn $3^{A P /-}$ ), the AP reporter identifies those cells that were programmed to express the particular Brn3 gene but from which that gene's coding region has been deleted. Data for Brn3a and Brn3b-null RGCs are described by Badea et al. (2009a); Figure 2, $A$ and $B$, presents the complete dataset for all three Brn3 genes. 


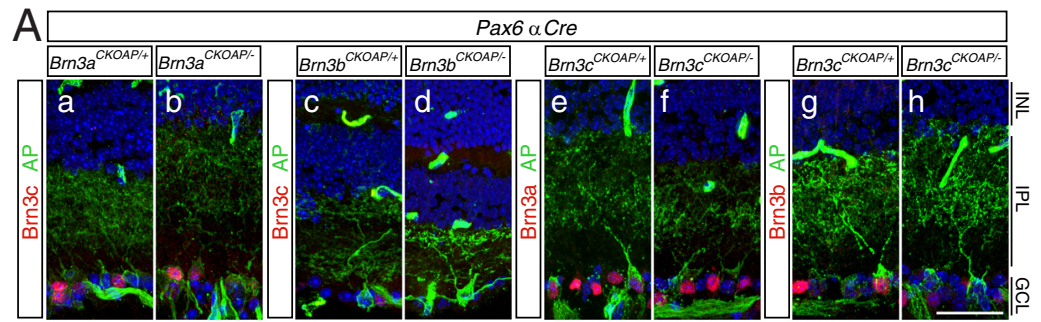

B
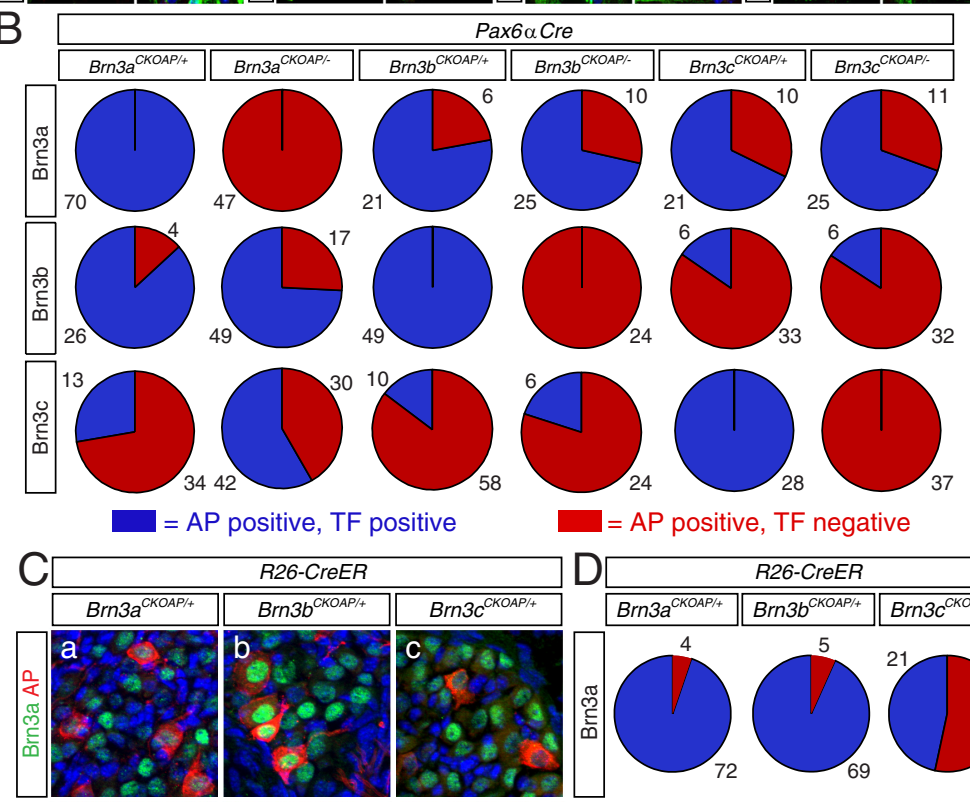

$=\mathrm{AP}$ positive, $\mathrm{TF}$ negative
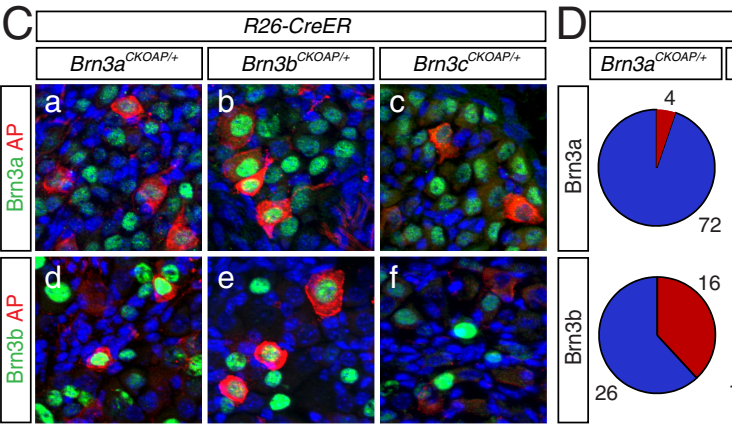

R26-CreER
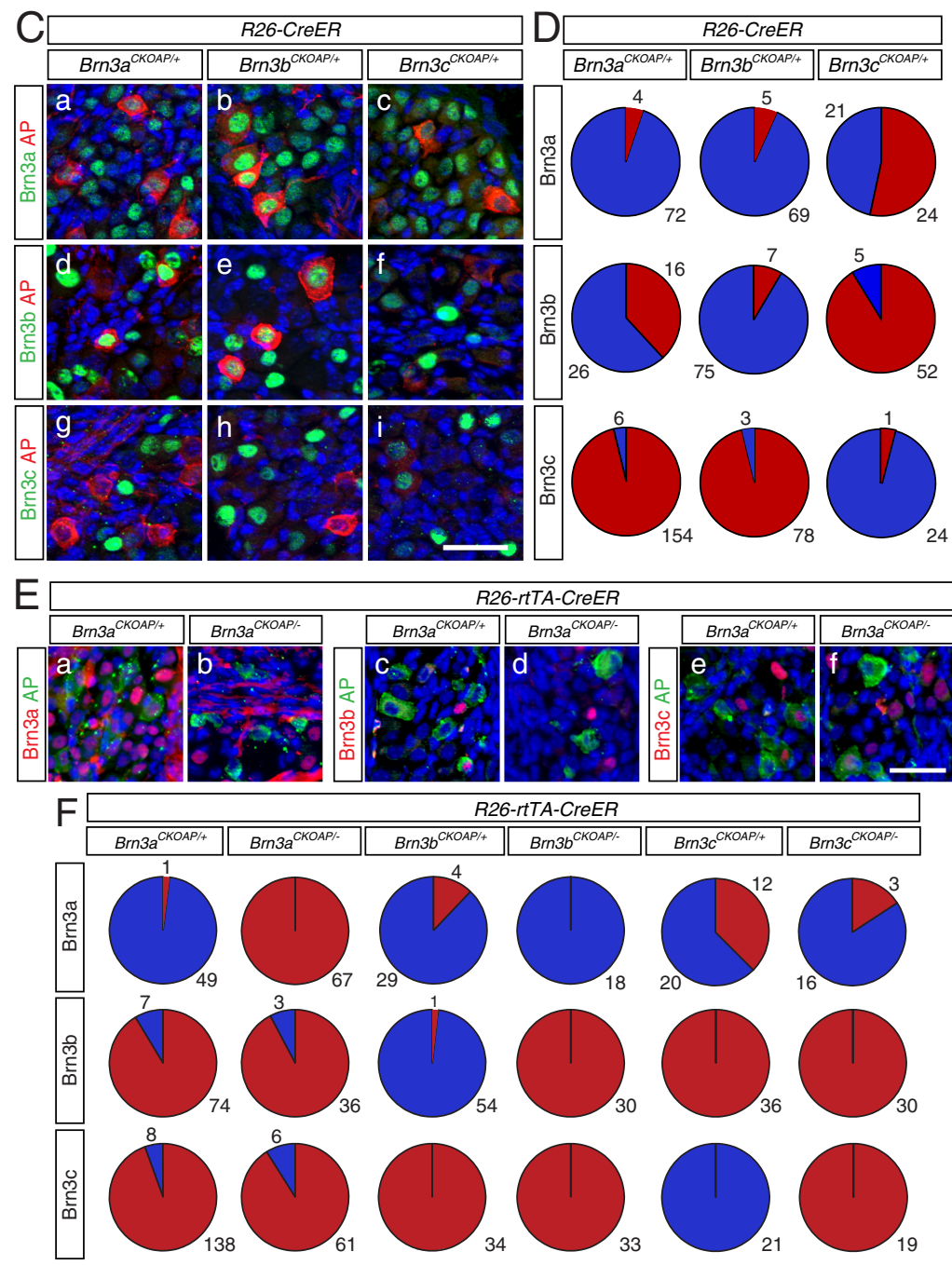

6-rtTA-CreER


Figure 2. Expression of $B r n 3 a, B r n 3 b$, and $B r n 3 c$ in $B r n 3 a^{A P /+}, B r n 3 a^{A P /-}, B r n 3 b^{A P /+}, B r n 3 b^{A P /-}, B r n 3 c^{A P /+}$, and $B r n 3 c^{A P /-}$ RGCS and DRG neurons determined by anti-AP and anti-Brn3 double immunostaining. $A$, Adult retina sections stained for cell surface AP (green) and nuclear Brn3a, Brn3b, or Brn3c (red). Note that green fluorescent anti-mouse secondary antibodies also decorate intraretinal capillaries. INL, Inner nuclear layer; IPL, inner plexiform layer; GCL, ganglion cell layer. Scale bar, $40 \mu \mathrm{m}$. $\boldsymbol{B}$,
As expected, all AP+ RGCs from $B r n 3 a^{A P /+}, B r n 3 b^{A P /+}$, and $B r n 3 c^{A P /+}$ retinas also exhibit nuclear immunoreactivity for the corresponding Brn3 family member, and all AP+ RGCs from $B r n 3 a^{A P /-}, B r n 3 b^{A P /-}$, and $B r n 3 c^{A P /-}$ retinas lack nuclear immunoreactivity for the corresponding Brn3 family member (Fig. 2A,B). With respect to crossregulation, loss of Brn3b has little effect on expression of $B r n 3 a$ or $B r n 3 c$, and loss of Brn3c has little effect on expression of $B r n 3 a$ or Brn3b. However, among $B r n 3 a^{A P /-}$ RGCs there is a statistically significant increase in the fraction of cells expressing Brn3c ( $p=0.0013)$ and a modest decrease that does not rise to statistical significance in the fraction of cells expressing Brn3b ( $p=0.20)$. These observations suggest that Brn3a may normally suppress Brn3c expression in a subset of RGCs.

\section{Expression patterns of Brn3 family members in DRG neurons}

We also determined the patterns of coexpression of Brn3 family members in DRG neurons. Figure 2, $C$ and $D$, shows the patterns of colocalization in $B r n 3 a^{A P /+}$, $B r n 3 b^{A P /+}$, and $B r n 3 c^{A P /+}$ DRG neurons at P5 from $B r n 3 a^{C K O A P /+} ; R 26 C r e E R$, $\mathrm{Brn} 3 \mathrm{~b}^{\mathrm{CKOAP} /+}$; R26CreER, or Brn3 $\mathrm{C}^{\mathrm{CKOAP} /+}$; R26CreER mice that had undergone sparse Cre-mediated recombination. We note that at P5 as many as $10 \%$ of $\mathrm{AP}+$ DRG neurons are not detectably immunostained for the transcription factor that corresponds to the AP knock-in allele (e.g., $10 \%$ of $B r n 3 b^{A P /+}$ neurons are not detectably stained with anti-Brn3b antibodies) (Fig. 2D). We ascribe this apparent discrepancy to the higher sensitivity of

\section{$\leftarrow$}

Quantification of the patterns of Brn3 immunostaining (labels at left) in adult WT and KO RGCs of the indicated genotypes (labels at top). Pie charts quantify the fraction of AP + cells that were positive (blue) or negative (red) for the indicated transcription factor (TF). The number of RGCs that were counted in each category is indicated. Data for Brn3a and Brn3b expression in Brn3 $a^{A P /+}$ and Brn3a $A^{A P /}-$ RGCs were described by Badea et al. (2009a) and are included here for completeness. Definitions of red and blue pie chart colors apply to $\boldsymbol{B}, \boldsymbol{D}$, and $\boldsymbol{F}$. C, P5 DRGs following mosaic Cremediated recombination in $B \mathrm{rm} 3 \mathrm{a}^{\mathrm{CKOAP} /+}, R 26 \mathrm{Cr}$ EER, Bm3b ${ }^{\mathrm{CKOAP} /+}$; R26CreER or Brn3C $C^{\text {KOAP/+ }}$;R26CreER mice stained for cell surface AP (red) and nuclear Brn3a, Brn3b, or Brn3c (green). Scale bar, 40 $\mu \mathrm{m} . \boldsymbol{D}$, Quantification of data from C; color code as in B.E, P0 -P1 DRGs following mosaic Cre-mediated recombination in Brn3a $a^{\text {CKOAPI+ }} ;$ R26rtTACreER, Brn3a $a^{\text {CKOAPI- }}$; R26rtTACreER, Brn36 $b^{\text {CKOAPI+ }} ;$ R26rtTACreER, Brn3b ${ }^{\text {CKOAPI- }}$; R26rtTACreER, Brn3 $3 \mathrm{CKOAPI+}^{+}$, R26rtTACreER, and Brn3C $\mathrm{CKOAPI-}^{\mathrm{C}} ;$ R26rtTACreER mice stained for cell surface AP (green) and nuclear Brn3a, Brn3b, or Brn3c (red). Scale bar, $40 \mu \mathrm{m}$. F, Quantification of data from $E$; color code as in $\boldsymbol{B}$. 

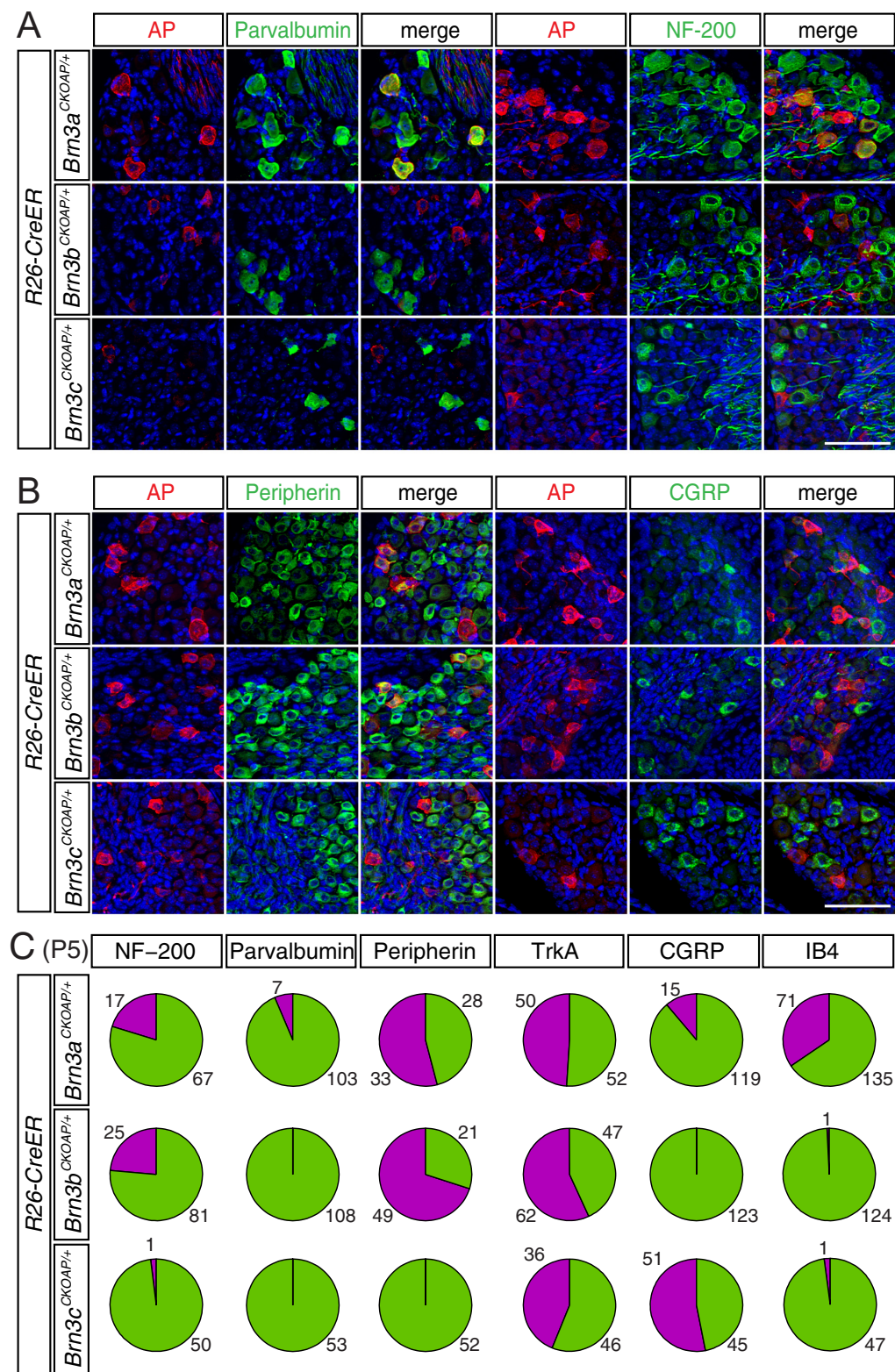

D (adult)

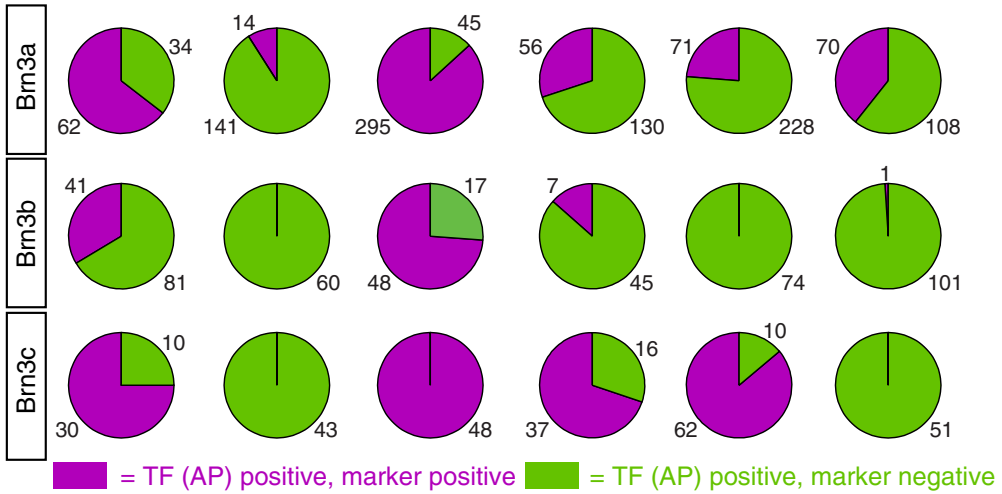

Figure 3. Correlation among $B r n 3 a, B r n 3 b$, and $B r n 3$ c expression and DRG neuron subtype as defined by molecular markers. $A$, $B$, Double immunostaining for AP (red) and the indicated molecular markers ( $g r e e n)$ in DRGs at P5 following mosaic Cre-mediated recombination in $B r n 3 a^{C K O A P /+} ; R 26 C r e E R, B r n 3 b^{C K O A P /+} ; R 26 C r e E R$, and Brn3 ${ }^{C K O A P /+} ;$;R26CreER mice. Scale bar, $40 \mu \mathrm{m}$. C, Quantification of data from $\boldsymbol{A}$ and $\boldsymbol{B}$. D, Quantification of adult WT DRGs using anti-Brn3a, anti-Brn3b, and anti-Brn3c immunostaining with the same series of markers as in $\boldsymbol{A}-\boldsymbol{C}$. Color code refers to $\boldsymbol{C}$ and $\boldsymbol{D}$.
AP compared with Brn3 immunostaining and the wide variation in Brn3 protein levels per cell. In comparing the patterns of Brn3 expression, RGCs and DRG neurons show several intriguing similarities: (1) there are far fewer Brn3c- than Brn3aor Brn3b-expressing neurons; (2) many neurons express both Brn3a and Brn3b; and (3) among Brn $3 \mathrm{c}$-expressing neurons, a larger fraction coexpress Brn $3 a$ than $B r n 3 b$ (Fig. 2A-D). The principal difference between RGC and DRG expression patterns is that, among DRG neurons, $B r n 3 a$ is expressed in nearly all neurons and $B r n 3 b$ and $B r n 3 c$ are rarely coexpressed.

A comparison of $B r n 3$ gene expression patterns in $B r n 3 a^{A P /+}$ versus $B r n 3 a^{A P /-}$, $B r n 3 b^{A P /+}$ versus $B r n 3 b^{A P /-}$ and $B r n 3 c^{A P /+}$ versus $B r n 3 c^{A P /-}$ DRGs at P0-P1 indicates that there is little cross-regulation among Brn3 family members; that is, loss of one Brn3 family member does not lead to repression or induction of other family members (Fig. $2 E, F$ ). In comparing $\mathrm{P} 0 / \mathrm{P} 1$ versus P5 DRG neurons (Fig. $2 C-F$ ), we observe a progressive increase in the fraction of $B r n 3 a^{A P /+}$ neurons that also express Brn3b ( 7 of 81 neurons at $\mathrm{P} 0 / \mathrm{P} 1$ versus 16 of 42 neurons at $\mathrm{P} 5 ; p=0.0002$ ), indicative of ongoing postnatal refinement within this subset of DRG neurons.

To relate the expression of Brn3 family members to functional DRG neuron subtypes during early postnatal development, we performed double labeling for a series of molecular markers and for $\mathrm{AP}$ in P5 $B r n 3 a^{A P /+}, B r n 3 b^{A P /+}$, and $B r n 3 c^{A P /+}$ DRGs (Fig. $3 A-C$ ). The same markers were also analyzed in adult WT DRGs using anti-Brn3a, anti-Brn3b, and antiBrn3c antibodies (Fig. 3D; and data not shown). The DRG markers consist of NF-200 (mechanoreceptors and proprioreceptors with large axon diameters), parvalbumin (proprioceptors), TrkA (small and medium diameter unmyelinated nociceptors and mechanoreceptors), CGRP (peptidergic nociceptors), IB4 (nonpeptidergic nociceptors), and peripherin (nociceptors and mechanoreceptors). TrkA is expressed in and required for the development of both peptidergic nociceptors (Marmigère and Ernfors, 2007) and a variety of mechanoreceptors (Fundin et al., 1997b; Cronk et al., 2002; Sedý et al., 2004).

As summarized in Figure 3, $C$ and $D$, the patterns of labeling at P5 and in the adult are distinctive for each Brn3 family member. Within the diverse set of $\mathrm{Brn} 3 \mathrm{a}$ expressing DRG neurons, all six markers are represented, both at P5 and in the adult. A seventh marker, tyrosine hydrox- 
ylase, which is present in $10-15 \%$ of adult mouse DRG neurons (Brumovsky et al., 2006), showed no colabeling at P5 with $B r n 3 b^{A P /+}$ and $B r n 3 c^{A P /+}$ DRG neurons. Among $124 \mathrm{Brn} 3 \mathrm{a}^{A P /+}$ neurons and 50 tyrosine hydroxylase-expressing neurons, only one neuron was possibly doublepositive. At P5, Brn3b-expressing DRG neurons express only NF-200, peripherin, and $\operatorname{TrkA}$ at appreciable frequency, and Brn3c-expressing neurons express only TrkA and CGRP at appreciable frequency.

In comparing P5 and adult DRGs, the main differences are as follows: (1) an increase among all three classes of adult Brn3-expressing DRG neurons in the proportion that express NF-200, an effect that is most dramatic among $\mathrm{Brn} 3 \mathrm{c}$-expressing neurons; (2) a conversion of all or nearly all Brn3c-expressing neurons from peripherin negative to peripherin positive; (3) an increase in the percentage of $\mathrm{Brn} 3 \mathrm{c}$ expressing neurons that express CGRP from $\sim 55 \%$ to $\sim 85 \%$; and (4) a decline in the proportion of Brn3a- and Brn3bexpressing neurons that express TrkA, with expression of TrkA persisting in a majority of Brn3c-expressing neurons. These changes between P5 and adulthood suggest that Brn3c-expressing neurons mature relatively late. Together, this analysis indicates that Brn3a-expressing DRG neurons encompass many, but not all, of the major classes of somatosensory neurons, Brn3b-expressing DRG neurons likely correspond to mechanoreceptors, and Brn3c-expressing DRG neurons likely correspond to peptidergic nociceptors.

Distinctive laminar targets in the dorsal horn of the spinal cord for Brn3a-, $B r n 3 b$-, and Brn $3 c$-expressing DRG neurons

The correlations described in the preceding paragraph imply that Brn3a-expressing DRG neurons should project to many laminae in the dorsal horn of the spinal cord, whereas Brn3b- and Brn3c-expressing DRG neurons should project to only one or a few laminae. To test these predictions, the projections of $B r n 3 a^{A P /+}, B r n 3 b^{A P /+}$, and $B r n 3 c^{A P /+}$ DRG neurons in the adult dorsal horn were visualized using AP immunostaining together with immunostaining for CGRP, IB4, or PKC $\gamma$, markers that define, respectively, peptidergic nociceptive laminae I and IIo, a nonpeptidergic nociceptive zone between laminae IIo and IIi, and mechanoreceptive lamina IIi (Zylka et al., 2005; Neumann et al., 2008). The central projections of Brn3a-expressing DRGs were distributed throughout the dorsal horn (Figs. $4 A, B$, $7 A$ ), consistent with the broad expression of Brn3a in DRG neurons. In contrast, the central projections of Brn3b- and Brn3cexpressing DRG neurons were narrowly targeted to the outer half of the PKC $\gamma$ lamina and to the CGRP lamina, respectively (Figs. $4 C-H, 7 A)$. These data are consistent with an assignment of
Brn3b-expressing DRG neurons as likely mechanoreceptors, based on the assignment of the PKC $\gamma$ lamina as a target area for non-noxious stimuli (Neumann et al., 2008), and Brn3cexpressing DRG neurons as likely peptidergic nociceptors.

\section{Visualizing afferent arbors of Brn3a-, Brn3b-, and Brn3c- expressing DRGs}

Among somatosensory neurons, the integration of physiological, morphological, and molecular properties is most advanced in the context of pain, temperature, and itch sensation mediated by TRP channels and the Mrgprd class of GPCRs (Zylka et al., 2005; Lumpkin and Caterina, 2007; Dussor et al., 2008; Basbaum et al., 2009; Cavanaugh et al., 2009; Liu et al., 2009; Rau et al., 2009). Largely missing, thus far, has been a morphologic analysis of somatosensory afferents beyond the structures of individual sensory terminals. In particular, there is very little information re- 
garding the size and geometry of the afferent arbors of individual somatosensory neurons. The paucity of data reflects several factors: (1) somatosensory afferents typically travel long distances from their cell bodies, thus hampering their visualization following injection of the soma with intracellular tracers; (2) immunostaining for somatosensory proteins or staining with nonspecific methods such as silver impregnation generally reveals a complex meshwork of afferent processes from which individual arbors cannot be reconstructed; and (3) many of the tissues within which sensory afferents reside-skin, muscle, the viscera, and connective tissue - are relatively thick and refractile, making it difficult to immunostain and image them in whole-mount preparations. This situation stands in marked contrast to the sophisticated morphologic analyses that have been conducted in the retina, where a relatively thin two-dimensional tissue offers ready access to physiologic recordings, cell filling, and immunochemical or histochemical staining in both flatmount and sectioned preparations (Masland, 2001; Dacey et al., 2003; Badea and Nathans, 2004).

To our knowledge, only one published study has used a genetically directed reporter to visualize the complete arbors of individual somatosensory afferents, that of Liu et al. (2007), in which skin afferents expressed an AP knockin at the MrgprB4 locus. AP histochemistry lends itself to visualizing skin afferents because of the high sensitivity of the AP reporter, the efficient diffusion of the low-molecular-weight AP substrate into relatively thick tissue samples, and the insolubility of the nitro-blue tetrazolium reaction product in the tissue clearing solvent benzyl benzoate:benzyl alcohol.

Individual afferent arbors of Brn3a-, Brn3b-, and Brn3cexpressing DRG neurons were visualized following extremely sparse Cre-mediated recombination with either of two CreER lines. Most of the experiments shown in Figure 5 used an IRESCreER cassette knocked into the 3' UTR of the gene coding for the neurofilament light chain (NFL-CreER) (Rotolo et al., 2008). For Figures $5 U, 6$, and 7, CreER was expressed from the ROSA26 locus under the control of the reverse Tet transactivator (rtTA), thus providing pharmacologic control over both transcription and nuclear translocation of Cre recombinase $\left(R 26^{r T A C r e E R}\right)$ (Badea et al., 2009b). As described below, NFL-CreER appears to be expressed in many types of DRG neurons as judged by the diversity of labeled Brn3a-expressing afferents in skin and muscle and the labeling of central Brn $3 a$-expressing projections throughout the dorsal horn of the spinal cord. This conclusion is also supported by the high degree of similarity in afferent arbor patterns observed between the NFL-CreER and R26 ${ }^{\text {rTACreER }}$ datasets; the latter presumably derives from ubiquitous expression of CreER.

In Figure 5, Brn $3 a^{\mathrm{CKOAP} /{ }^{+}}$; NFL-CreER, $\mathrm{Brn} 3 b^{\mathrm{CKOAP} /+}{ }^{\mathrm{N}} \mathrm{NFL}-$ $\mathrm{CreER}$, and $\mathrm{Brn} 3 \mathrm{C}^{\mathrm{CKOAP} /+}$;NFL-CreER fetuses were exposed to $0-200 \mu \mathrm{g}$ of $4 \mathrm{HT}$ during late gestation and then abdominal skin from these mice at $\mathrm{P} 0-\mathrm{P} 3$ was processed for AP histochemistry. Neonatal rather than adult skin was analyzed because the pigment content, large size, and high density of adult hair follicles interfere with imaging of labeled afferents. In the mouse, many mechanoreceptors that innervate the skin appear to be physiologically and anatomically mature by the early postnatal period (Woodbury et al., 2001; Woodbury and Koerber, 2007). Figure $5 A$ illustrates the specificity of AP expression in a $200 \mu \mathrm{m}$ vibratome section through a P1 Brn $3 a^{C K O A P /+} ; \mathrm{NFL}-\mathrm{CreER}$ mouse. AP activity is restricted to DRG cell bodies, afferent fibers in the dorsal roots, projections throughout the dorsal horn of the spinal cord, and occasional multipolar neurons within the spinal cord.
Figure $5 B-E$ illustrates the diversity of nondermal afferents labeled in $\mathrm{Brn}_{3} \mathrm{a}^{\mathrm{CKOAP} /{ }^{+}}$;NFL-CreER mice. Labeled afferents in the P1 foot, adult esophagus, and P1 abdominal wall terminate in enlarged structures, presumably tendon organs (foot) or muscle spindles (esophagus and abdominal wall) (Fig. $5 B, D, E$ ). In the adult diaphragm, the termini of the highly branched afferents are not obviously enlarged (Fig. 5C).

In flatmounts of $\mathrm{Brn} 3 \mathrm{a}^{\mathrm{CKOAP} /{ }^{+}} ; \mathrm{NFL}-\mathrm{CreER} \mathrm{P} 1$ skin, APstained arbors vary in size from single dense $\mathrm{C}$-shaped endings associated with hair follicles (likely lanceolate endings) (Fig. $5 F, L)$ to arbors with $>100$ branches and a diameter of $\sim 1 \mathrm{~mm}$ (Fig. $5 \mathrm{M}, N$ ). A range of intermediate sizes is also seen (Fig. $5 G-$ $K)$, as well as individual arbors with both lanceolate and nonlanceolate endings (Fig. 5M). Similar analyses of $\mathrm{Brn}_{3} \mathrm{~b}^{\mathrm{CKOAP} /+}$; NF-LCreER P1 skin show a more limited range of labeled arbor types, with few very large arbors and many arbors with single lanceolate endings or with a mixture of lanceolate and nonlanceolate endings (Fig. 5O-T), as well as sensory endings in the glabrous skin of the footpad (Fig. $5 U$ ). Brn3b is also expressed in all or nearly all spiral ganglion neurons, as judged by the density of fibers targeting the organ of Corti in a whole-mount $\mathrm{Brn} 3 \mathrm{~b}^{\mathrm{AP} /+}$ P1 cochlea (Fig. $5 \mathrm{~V}$ ). Brn $3 \mathrm{C}^{\mathrm{CKOAP} /+}$;NFL-CreER P1 skin flatmounts show an even further reduction in the morphologic diversity of labeled sensory arbors, with almost all labeled afferents exhibiting a coarsely branched structure devoid of follicleassociated endings (Fig. $5 W-Y$ ). In $B r n 3 c^{C K O A P}$ skin, AP is expressed at low level in a semicircle of cells_-presumably Merkel cells_-surrounding each guard hair (Fig. $5 W-Y$, red arrows). These AP-expressing cells are not contiguous with labeled afferents, and they are readily distinguished from the more compact semicircular follicle-associated C-shaped endings (Fig. 5O-T). AP expression in Merkel cells appears to derive from low-level read-through transcription into the $\mathrm{AP}$ coding region at the unrecombined $B r n 3 c^{C K O A P}$ locus; a similar pattern of low-level read-through is seen for $B r n 3 a^{C K O A P}$ and $B r n 3 b^{C K O A P}$ loci in RGCs.

\section{Three-dimensional reconstruction and morphologic classification of afferent arbors in the skin}

To more rigorously characterize the morphologies of individual sensory arbors, we have reconstructed representative examples from sparsely labeled $B r n 3 a^{C K O A P /+} ; R 26^{r t T A C r e E R /+}$ and $B r n 3 b^{C K O A P /+} ; R 26^{r t T A C r e E R /+}$ abdominal skin at P1 (Fig. 6). The colored outlines in Figure 6 indicate the patterns of Brn3a, Brn3b, and/or Brn $3 c$ expression among the various morphologic classes. Arbors from DRG neurons that express $B r n 3 c$, as well as a subset that express $B r n 3 a$, cover a large area, branch sparsely, stratify either broadly within the dermis (Fig. 6A) or narrowly near the dermal-epidermal boundary (Fig. $6 B$ ), and do not make contacts with hair follicles. Arbors from DRG neurons that express Brn3b, as well as a subset that express $B r n 3 a$, branch more densely and, in most cases, make one or more C-shaped contacts with hair follicles (Fig. 6C-H). Arbors from DRG neurons that express Brn3a exclusively are diverse, including examples that cover a large area with numerous dense branches, stratify either narrowly near the dermal-epidermal boundary (Fig. $6 J$ ) or more deeply (Fig. 6I,L), and make few or no contacts with hair follicles. Also in the Brn3aonly group are arbors that contact hair follicles at more than one depth (Fig. $6 \mathrm{~K}$ ). The great diversity of dermal and nondermal sensory afferents that express $B r n 3 a$ is consistent with the nearly ubiquitous expression of $\mathrm{Brn} 3 \mathrm{a}$ in DRG neurons (Figs. 2, 3) and the large number of dorsal horn laminae targeted by these neurons (Figs. 4, 5A, 7A). 


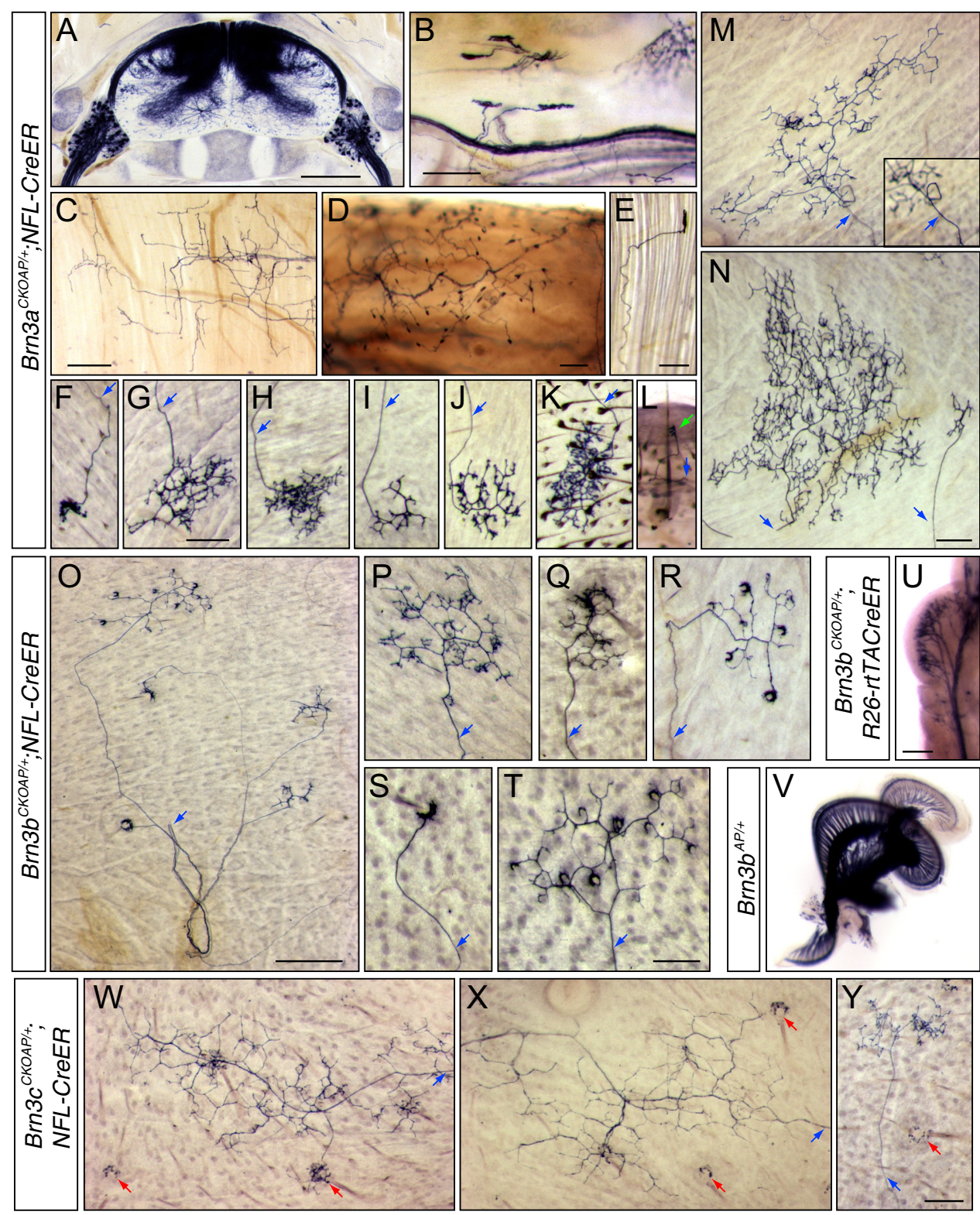

Figure 5. Individual $B r n 3 a^{A P /+}, B r n 3 b^{A P /+}$, and $B r n 3 c^{A P /+}$ somatosensory arbors visualized histochemically following sparse Cre-mediated recombination. $A-N, B r n 3 a^{C K O A P /+}$ afferents. $A, 200$ $\mu \mathrm{m}$ transverse section of $\mathrm{P} 1$ spinal cord and DRGs. In addition to DRG cell bodies and their processes, several large multipolar interneurons are labeled within the spinal cord. $B-E$, Innervation of muscle and tendons: hemisected P1 foot with the palmar surface at the bottom $(\boldsymbol{B})$; adult diaphragm $(\boldsymbol{C})$ and adult esophagus $(\boldsymbol{D})$; and isolated muscle spindle in subdermal muscle at P1 (E). $\boldsymbol{F}-\boldsymbol{N}$, P1 abdominal skin flatmounts showing individual sensory arbors $(\boldsymbol{F}-\boldsymbol{K}, \boldsymbol{M}, \boldsymbol{N})$; tangential section of P1 skin showing a guard hair with a single sensory ending (green arrow) (L). $\boldsymbol{F}-\boldsymbol{N}, \mathrm{Blue}$ arrows indicate individual afferent fibers. $\boldsymbol{F}$, A single elaborate follicle associated ending. $\boldsymbol{M}$, A large arbor with a mixture of follicle-associated and nonassociated endings. Scale bars: $A, C, 500 \mu \mathrm{m} ; \boldsymbol{B}, \boldsymbol{D}, \boldsymbol{E}$, $\boldsymbol{G}, \boldsymbol{N}, 200 \mu \mathrm{m} . \boldsymbol{F}-\boldsymbol{L}$ are at the same scale, and $\boldsymbol{M}$ and $\boldsymbol{N}$ are at the same scale. $\mathbf{O}-\boldsymbol{V}, B r n 3 b^{C K O A P /+}$ afferents. $\mathbf{O}-\boldsymbol{T}, \mathbf{P} 1$ abdominal skin flatmounts. Blue arrows indicate individual afferent fibers. $\boldsymbol{U}$, Innervation of glabrous skin in the $\mathrm{P} 1$ foot in cross section. $\boldsymbol{V}, B r n 3 b$-expressing fibers in a $\mathrm{P} 1 \mathrm{Brn} 3 \mathrm{~b}^{A P /+}$ cochlea (following germline recombination) innervate sensory hair cells in the organ of Corti.

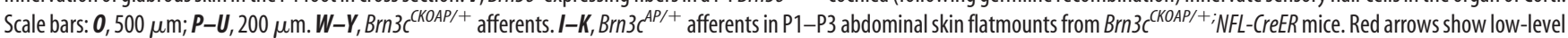
read-through AP expression from the un-recombined $B r n 3{ }^{C K O A P}$ allele in Merkel cells adjacent to each guard hair. Blue arrows indicate individual afferent fibers. Scale bar, $200 \mu \mathrm{M}$.

\section{Loss of Brn3a but not Brn3b or Brn3c causes a loss of DRG neuron subtypes}

Previous genetic analyses of Brn3a function in the somatosensory system have been restricted to the prenatal period because $\mathrm{Brn} \mathrm{a}^{-1-}$ mice die shortly after birth. Here we present a postnatal analysis of Brn3a function, based on the availability of the $B r n 3 a^{C K O A P}$ allele, which permits individual, histochemically marked $B r n 3 a^{A P /-}$ neurons to be produced by sparse Cremediated recombination at any time during development in $B r n 3 a^{C K O A P /-} ; R 26^{r T A C r e E R /+}$ embryos. Since the vast majority of Brn3a-expressing neurons do not undergo Cre-mediated recombination with the doxycycline and 4HT regimen used here (see
Materials and Methods), the resulting mice can be studied at any postnatal age. Moreover, the phenotypes exhibited by individual $B r n 3 a^{A P /-}$ DRG neurons in the $B r n 3 a^{C K O A P /-} ; R 26^{r T A C r e E R /+}$ background are presumably cell autonomous since almost all of the neighboring neurons are phenotypically WT. This last point is of special relevance because the massive neuronal loss observed in $\mathrm{Brn}_{3} \mathrm{a}^{-1-}$ DRGs would be expected to produce cellnonautonomous effects arising from reduced competition with neighboring DRG neurons for target innervation, aberrant axonal pathfinding by neighboring mutant neurons, or a large local concentration of apoptotic cells. While cell-nonautonomous effects are of interest in their own right, experiments conducted in 


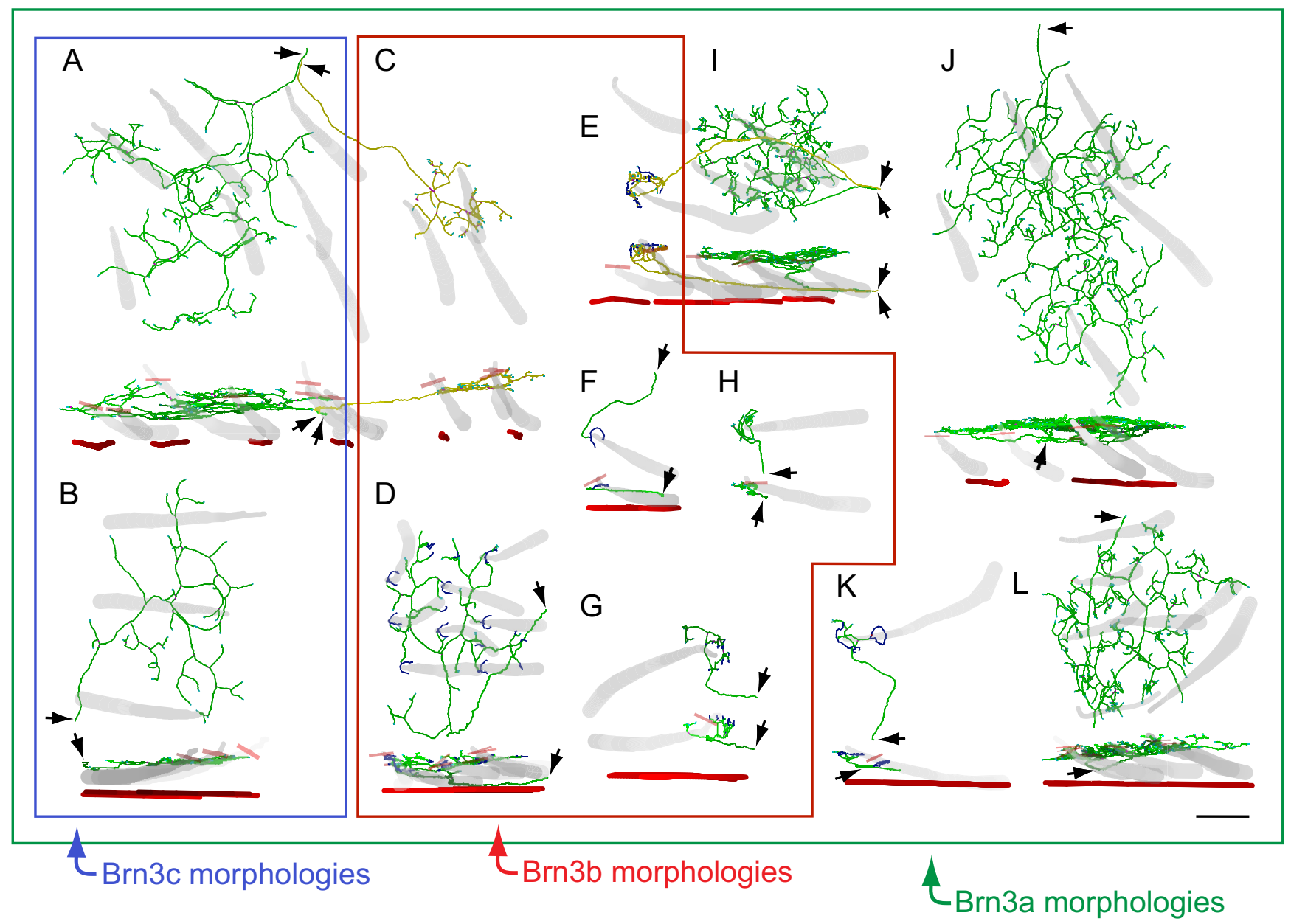

Figure 6. Three-dimensional reconstructions of afferent arbors from Brn3a-, Brn3b-, and Brn3c-expressing DRG neurons in P1-P3 skin. $\boldsymbol{A}-\boldsymbol{L}$, Each dendritic arbor reconstruction is assigned a letter $(\boldsymbol{A}-\boldsymbol{L})$, and two projections — one in the plane of the skin (top) and one perpendicular to that plane (bottom) — are shown. For the territories encompassing arbors $\boldsymbol{A}$ and $\boldsymbol{C}$ and arbors $\boldsymbol{E}$ and $\boldsymbol{I}$, the two neighboring arbors are shown in yellow and green. Outlines of guard hair follicles are shown in gray, and the point of contact between each follicle and the epidermis is marked by a pink horizontal line in the transverse projection. Stratification levels of individual subdermal muscle fibers are represented by dark red bars in the transverse projections. The most proximal point of each afferent fiber reconstruction is marked by a black arrow. Small C-shaped hair follicle-associated structures are present in arbors $\boldsymbol{D}, \boldsymbol{F}$, and $\boldsymbol{K}$, and are highlighted in blue; more elaborate hair follicle associated structures are present in $\boldsymbol{E}, \boldsymbol{G}$, and $\boldsymbol{H}$. Distinct morphological types representative of $B r n 3 a^{A P /+}, B r n 3 b^{A P /+}$, and $B r n 3 C^{A P /+}$ arbors are outlined in green, red, and blue, respectively. All morphologies were observed among $B r n 3 a^{A P /+}$ arbors. Types $A$ and $B$ were also observed among $B r n 3 C^{A P /+}$ arbors, types $\boldsymbol{C}-\boldsymbol{H}$ were also observed among $B r n 3 b^{A P /+}$ arbors, and types $\boldsymbol{I} \boldsymbol{L}$ were unique to $B r n 3 a^{A P /+}$ arbors. The specific examples shown are derived from $B r n 3 a^{C K O A P /+} ; R 26^{r t T A C r e E R /+}$ $(\boldsymbol{A}-\boldsymbol{F}, \boldsymbol{H}-\mathbf{L})$ and Brn36 $b^{\text {CKOAP/+ }} ; R 26^{\text {rtTACreER/+}}(\mathbf{G})$ P1 skins. Scale bar, $100 \mu \mathrm{m}$.

$\mathrm{Brn} 3 \mathrm{a}^{-/-}$mice cannot distinguish autonomous from nonautonomous effects.

As an initial step in defining the cell-autonomous phenotypes associated with loss of $B r n 3 a, B r n 3 b$, and $B r n 3 c$, we compared the territories targeted by AP-expressing DRG neurons in the dorsal horn of adult Brn $3 a^{C K O A P /+} ; R 26^{\text {rTACreER }}$ versus Brn3aCKOAP/- ; $R 26^{r T A C r e E R}, B r n 3 b^{C K O A P /+} ; R 26^{r T A C r e E R}$ versus $B r n 3 b^{C K O A P /-}$; $R 26^{r \text { TACreER }}$, and $\mathrm{Brn} 3 \mathrm{C}^{\mathrm{CKOAP/+}} ; \mathrm{R} 26^{\text {rTACreER }}$ versus Brn $3 \mathrm{C}^{\mathrm{CKOAP} /-}$; $R 26^{r T A C r e E R /+}$ spinal cords under conditions of sparse Cre-mediated recombination (Fig. 7A). While no differences were seen between $B r n 3 b^{A P /+}$ and $B r n 3 b^{A P /-}$ projections or between $B r n 3 c^{A P /+}$ and $B r n 3 c^{A P /-}$ projections, $B r n 3 a^{A P /+}$ and $B r n 3 a^{A P /-}$ projections differed markedly, with the latter showing a large zone of hypoinnervation (Fig. 7A, red arrowhead). Similarly, in early postnatal skin, a comparison between $B r n 3 b^{A P /+}$ and $B r n 3 b^{A P /-}$ arbors or between $B r n 3 c^{A P /+}$ and $B r n 3 c^{A P /-}$ arbors showed no apparent differences in density or in the types of morphologies, whereas a comparison between $B r n 3 a^{A P /+}$ and $B r n 3 a^{A P /-}$ skin showed a reduced density of $\mathrm{AP}+$ arbors in the Brn3 $a^{A P /-}$ sample (data not shown). Strikingly, the morphologies of $B r n 3 a^{A P /-}$ arbors represent only a subset of the
$B r n 3 a^{A P /+}$ arbor morphologies. In particular, the $B r n 3 a^{A P /-}$ skin is nearly devoid of AP $+\mathrm{C}$-shaped endings that contact hair follicles, a difference that is apparent even when comparing regions in which the overall density of $\mathrm{AP}+$ arbors in the $\mathrm{Brn} 3 \mathrm{a}^{\mathrm{CKOAP/}-} ; \mathrm{R} 26^{\text {rTACreER }}$ skin is comparable or greater to that in the $B r n 3 a^{C K O A P /+}$; $R 26^{\text {rTACreER }}$ control skin (Fig. $7 B, D$ ). Many of the AP+ arbor morphologies that remain in $\mathrm{Brn} 3 a^{\mathrm{CKOAP} /-} ; \mathrm{R} 26^{\text {rTACreER }}$ skins conform to types observed in control $\mathrm{Brn} 3 a^{\mathrm{CKOAP/+}} ; R 26^{\text {rTACCreER }}$ skins, as seen, for example, in comparing Figures $6 C$ and $7 C$. Thus, loss of $B r n 3 a$ leads to a selective loss and/or fate switch of hair follicleassociated terminals.

\section{Discussion}

The experiments described here, together with those reported in Badea et al. (2009a) and Badea and Nathans (2011), use a set of three Brn3-null alleles and three AP-expressing Brn3 conditional alleles, together with sparse Cre-mediated recombination, to define the overlapping patterns of $\mathrm{Brn} 3$ gene expression in RGCs and somatosensory neurons, the manner in which the patterns of gene expression correlate with morphologically distinct neuronal 



Figure 7. Loss of Brn3a but not $B r n 3 b$ or Brn3c causes a loss of dorsal horn projections and hair follicle-associated sensory endings in the skin. $A$, AP histochemistry of vibratome sectioned spinal

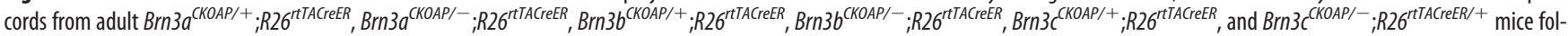
lowing Cre-mediated recombination at E9.5. Red arrow points to the loss of Brn3a $a^{C K O A P /-}$ fibers in the dorsal horn. $B, A P$ histochemistry of flatmounted abdominal skins from Brn3a ${ }^{C K O A P /+}$; $R 26^{\text {rtTACreER }}$ and Brn3 $a^{\text {CKOAP/- }} ;$ R2 $6^{\text {tTAACreER }} \mathrm{P} 1$ mice. Red arrowheads point to AP+ hair follicle-associated C-shaped sensory endings; these endings are common among Brn $3 a^{A P /+}$ arbors (left) but are extremely rare among $B r n 3 a^{A P /-}$ arbors (right). The right panel shows a region of $B r n 3 a^{C K O A P /-} ; R 26^{r \text { tTACreER }}$ skin with a somewhat higher density of AP+ sensory arbors relative to the $B r n 3 a^{C K O A P /+} ; R 26^{r T A C C r e E R}$ skin in the left panel to emphasize the point that that the low density of $C$-shaped endings does not arise from a lower density of sensory arbors. $C$, Flatmount images of an isolated $B r n 3 a^{A P /-}$ sensory arbor (two focal planes at left) and its reconstruction (Fig. 6, right; as), with relatively simple branching and small area, similar to the example shown in Figure $6 C$. D,

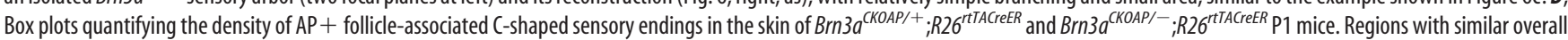
densities of labeled arbors were chosen for comparison. The central red mark is the median, the blue edges of the box are the 25 th and 75 th percentiles, and the whiskers extend to the most extreme data points. For each genotype, eight fields of $2.6 \times 2.6 \mathrm{~mm}$ were scored. $p=1.56 \times 10^{-4}$. Scale bars: $A, 300 \mu \mathrm{m} ; \boldsymbol{B}, C, 100 \mu \mathrm{m}$.

types, and the consequences for these neurons of deleting each $B r n 3$ gene. Among RGCs, we observe that Brn3 gene expression correlates with the patterns of dendritic arborization and lamination in the inner plexiform layer and the patterns of axonal projections to retinorecipient targets in the brain. Among somatosensory neurons, we observe subtype-specific expression of $B r n 3 b$ and $B r n 3 c$. We also demonstrate the general utility of sparse, genetically directed reporter expression and histochemical labeling for visualizing individual somatosensory afferent arbors, an approach that should aid in classifying somatosensory neurons and determining the sizes and structures of their receptive fields.

\section{Brn3 gene expression and somatosensory neuron identity}

The essential role of Brn3a in the development and survival of somatosensory neurons was appreciated in the initial analyses of $B r n 3 a^{-/-}$mice (McEvilly et al., 1996; Xiang et al., 1996). Subsequent work has refined this picture by characterizing the downregulation of a variety of somatosensory cell-type-specific molecular markers, including Trk receptors, in the DRG and TG of $\mathrm{Brn3a}^{-1-}$ mice (Huang et al., 1999; Ichikawa et al., 2002, 2004, 2005; Ma et al., 2003), by demonstrating defects in pathfinding of somatosensory afferents (Eng et al., 2001) and by showing that, either directly or indirectly, Brn3a represses genes associated with neurogenesis and induces genes associated with terminal differentiation, including Runx 1 and Runx3 (Lanier et al., 2009; Dykes et al., 2010). The nearly complete loss of hair follicle-associated endings observed here among $B r n 3 a^{A P /-}$ afferents is consistent with the idea that Brn3a controls a program of Runx and Trk receptor expression that is required for mechanosensory neuron development and/or survival (Dykes et al., 2010).

Before the present work, the relationship between Brn3b and $B r n 3 c$ expression and somatosensory neuronal subtypes was largely unexplored. Although the immunohistochemical profiles of DRG cell bodies, morphologies of afferent arbors in the skin, and locations of target laminae in the dorsal horn suggest that $B r n 3 b$ is expressed principally in hair follicle-associated mechanoreceptors and that $B r n 3 c$ is expressed principally in peptidergic 


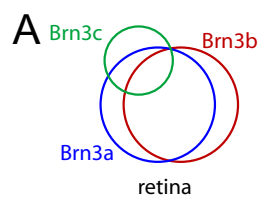

B

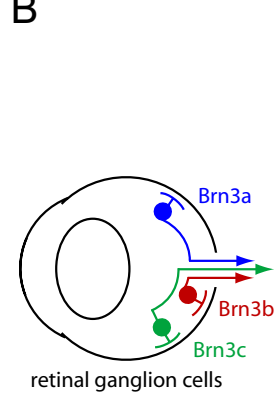

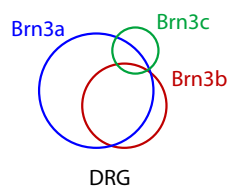

DRG
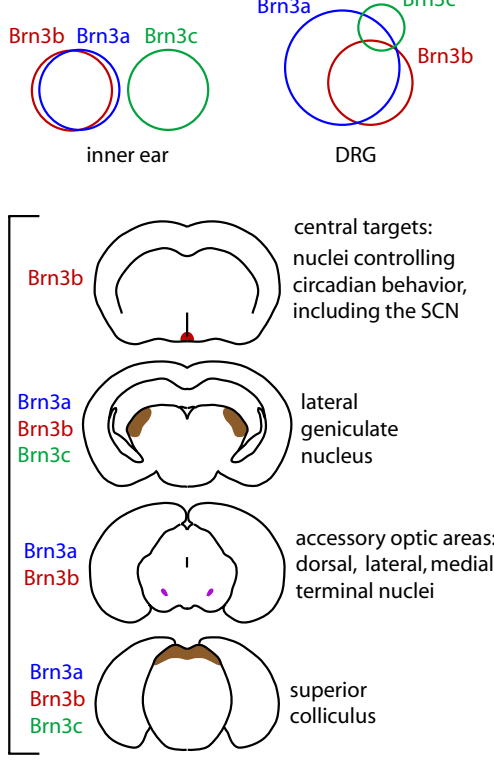
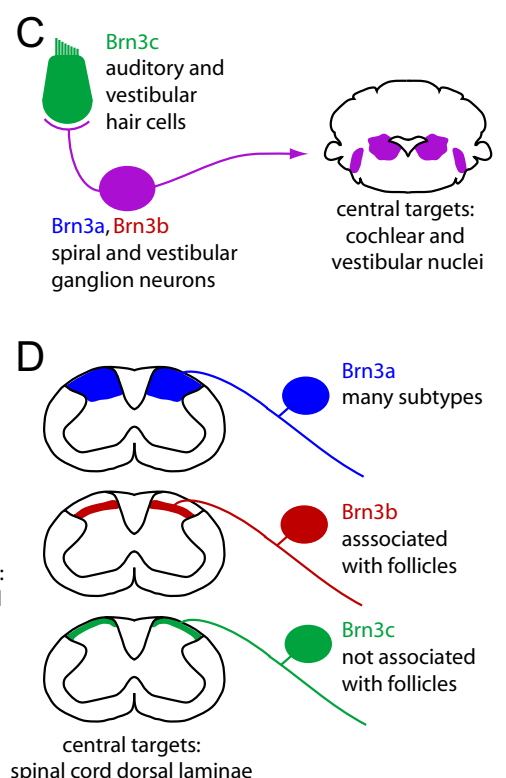

Figure 8. Combinatorial expression of $B r n 3 a, B r n 3 b$, and $B r n 3 c$ in projection neurons in the visual, auditory/vestibular, and somatosensory systems. $A$, Venn diagrams summarizing the relative numbers of expressing neurons and the patterns of overlapping expression among Brn3 family members in the retina, inner ear, and DRG. $\boldsymbol{B}$, Central targets of RGCs that express different combinations of $B r n 3 a, B r n 3 b$, and Brn3c. For illustrative purposes only a subset of the many accessory optic areas is shown. For example, the central targets that control pupil constriction are not shown; these receive input from Brn3b-expressing RGCs and are functionally impaired in Brn3b-/- mice (Badea et al., 2009a). C, In the auditory and vestibular systems, sensory hair cells express Brn3c (Xiang et al., 1997), and most or all spiral and vestibular ganglion cells express both Brn3a and Brn3b (Huang et al., 2001). D, In the somatosensory system, Brn3a is expressed by all or nearly all classes of sensory neurons, Brn3b is expressed by sensory neurons that have follicle-associated C-shaped endings, and Brn3c is expressed by sensory neurons that have endings not associated with hair follicles.

nociceptors, a definitive assignment of sensory types must await an electrophysiologic characterization of the stimulus-response characteristics of these neurons. The persistence of each of these cell types upon elimination of the associated Brn3 protein suggests that, unlike Brn3a, Brn3b and Brn3c may play a relatively subtle role in the somatosensory system, perhaps conferring aspects of molecular identity, but not determining subtype-specific morphology, central target specificity, or survival.

\section{Genetically directed sparse labeling as a tool for characterizing neuronal morphology in mice}

Our analyses of $B r n 3$ expression and function have relied on the use of sparse Cre-mediated Brn3 deletion coupled to activation of an AP reporter. This strategy offers several experimental advantages over the use of conventional null alleles or conditional alleles that do not generate marked cells. First, it permits mosaic mice to survive beyond the age at which homozygous null mutants die. For Brn $3 a^{-/-}$mice, death occurs in the neonatal period, a severe limitation for the analysis of retinal development, much of which occurs postnatally. Second, the sparse recombination strategy limits the phenotypic analysis to cell-autonomous effects, since the vast majority of the cells surrounding the rare $\mathrm{AP} /-$ cell are phenotypically WT. As noted in the Results section, in $B r n 3 a^{-1-}$ embryos the large numbers of dying DRG and TG neurons and/or the reduced competition for peripheral and central targets among the surviving DRG and TG neurons could produce cell-nonautonomous effects. A similar argument applies to the $B r n 3 b^{-/-}$retina, where $\sim 70 \%$ of RGCs eventually die. Third, by using pharmacologic control of Cre recombinase-in the present study, a dual doxycycline and 4HT strategy (Badea et al., 2009b) - the rare recombination events that lead to loss of gene function can be precisely timed. Finally, the sparse recombination method permits single-cell morphologic analysis by revealing a Golgi-like image of neuronal processes, either in
$\mathrm{AP} /+$ or AP/ - cells, the latter being null for the protein of interest but expressing the AP reporter by virtue of continued activity of the Brn3 promoter. With respect to sparse visualization of somatosensory afferents and central projections, the combination of Brn3a ${ }^{C K O A P}$ and NFL-CreER might be generally useful as a tool for surveying these structures in the context of surgical, toxicologic, genetic, or other experimental perturbations.

\section{Combinatorial expression of the Brn3 family in the visual,} somatosensory, and auditory/vestibular systems

Figure 8 summarizes the patterns of Brn3a, Brn3b, and Brn3c expression in the WT inner ear, retina, and DRG/TG. The Venn diagrams in Figure $8 \mathrm{~A}$ illustrate both the relative numbers of neurons expressing each Brn3 gene and the extent of overlap of $B r n 3$ gene expression among these neurons. In most cases, the $\mathrm{Brn} 3$ genes are expressed in the projection neurons that communicate information from the primary sensory structures to the brain or spinal cord (Fig. $8 B-D$ ), the two exceptions being the expression of $\mathrm{Brn} 3 \mathrm{c}$ in vestibular and auditory sensory hair cells (Fig. 8C) and in Merkel cells (Fig. $5 W-Y$ ). The general pattern of expression in projection neurons applies regardless of whether the Brn3-expressing cells are or are not primary sensory neurons or whether they are derived from surface ectoderm (spiral and vestibular ganglia), the neuroectoderm (DRG/TG), or neural tube (retina). Conceptualized in this manner, the logic of Brn3 expression suggests an evolutionary equivalence of RGCs, primary somatosensory neurons, and auditory and vestibular ganglion neurons.

How do the patterns of Brn3 gene expression relate to the evolution of increasingly complex sensory structures? It is reasonable to suppose that the primordial architecture of all sensory neurons initially resembled that seen in present-day nociceptors: the neuron that was the primary receiver of sensory information also projected directly to a central target. Following this logic, we 
imagine that the two outer layers of neurons in the trilayered vertebrate retina represent a later addition of specialized photoreceptors and interneurons. Consistent with this view, presentday vertebrate retinas contain a minor class of intrinsically photosensitize RGCs (ipRGCs). The ipRGCs mediate nonimage-forming visual functions such as circadian entrainment and pupil constriction (Güler et al., 2008), and they may represent the last relics of a primordial monolayer retina. Analogous arguments apply to the auditory and vestibular systems: primordial mechanosensory neurons may have projected directly to their central targets, and only later acquired a specialized epithelial partner-hair cells in the auditory/vestibular system and a variety of specialized epithelial cells in mechanosensory end organs in the skin, muscle, tendons, and viscera-to enhance their sensitivity. In this regard, it is striking that $B r n 3 c$ is not only expressed in auditory hair cells (Xiang et al., 1997) but is also expressed in Merkel cells (Fig. $5 W-Y$, red arrows). This serendipitous finding is consistent with a growing body of evidence demonstrating that Merkel cells_-specialized skin epithelial cells that synapse onto mechanosensory afferents — share molecular, morphologic, and functional similarities with auditory hair cells (Lumpkin and Caterina, 2007). As Brn3c is only required in the final stages of inner ear sensory hair cell differentiation (Xiang, 1998), these data suggest that Brn3c may play a general role in promoting the mechanosensory differentiation of specialized epithelial cells.

A further inference from the suggested evolutionary equivalence of RGCs, primary somatosensory neurons, and auditory and vestibular ganglion neurons is that there may be a corresponding equivalence in the logic of information processing at their initial CNS targets. Thus, the separation of somatosensory submodalities by targeting of DRG axons to distinct laminae in the dorsal horn of the spinal cord may be analogous to the separation of visual information streams produced by targeting of RGC axons to different retino-recipient regions in the diencephalon, or to the separation of auditory and vestibular inputs by targeting of spiral and vestibular ganglion axons to the cochlear and vestibular nuclei in the brainstem.

Functions analogous to those of mammalian $\mathrm{Brn} 3$ genes are seen in the single Brn3 homologs in Caenorhabditis elegans (Unc86) and Drosophila melanogaster (Acj6). Unc86 is required both for the production and differentiation of primary touchsensitive neurons and the correct functioning of the chemosensory AIZ interneurons (Duggan et al., 1998; Sze and Ruvkun, 2003). Acj6 is required for specifying the identity of primary olfactory receptor neurons, at the level of olfactory receptor gene choice and at the level of axon targeting to the appropriate glomerulus (Komiyama et al., 2004; Bai et al., 2009). Intriguingly, differential splicing of the Acj6 gene generates multiple isoforms with distinct activities in olfactory receptor neuron specification (Bai and Carlson, 2010). Initial steps have been taken to identify transcriptional targets of Unc86, Acj6, and the mammalian Brn3s (Erkman et al., 2000; Eng et al., 2004, 2007; Mu et al., 2004; Lanier et al., 2009; Dykes et al., 2010). It will be of great interest to compare these targets both between species and across sensory modalities.

\section{References}

Badea TC, Nathans J (2004) Quantitative analysis of neuronal morphologies in the mouse retina visualized by using a genetically directed reporter. J Comp Neurol 480:331-351.

Badea TC, Nathans J (2011) Morphologies of mouse retinal ganglion cells expressing transcription factors Brn3a, Brn3b, and Brn3c: analysis of wild type and mutant cells using genetically-directed sparse labeling. Vision Res 51:269-279.

Badea TC, Wang Y, Nathans J (2003) A noninvasive genetic/pharmacologic strategy for visualizing cell morphology and clonal relationships in the mouse. J Neurosci 23:2314-2322.

Badea TC, Cahill H, Ecker J, Hattar S, Nathans J (2009a) Distinct roles of transcription factors brn3a and brn3b in controlling the development, morphology, and function of retinal ganglion cells. Neuron 61:852-864.

Badea TC, Hua ZL, Smallwood PM, Williams J, Rotolo T, Ye X, Nathans J (2009b) New mouse lines for the analysis of neuronal morphology using CreER(T)/loxP-directed sparse labeling. PLoS One 4:e7859.

Bai L, Carlson JR (2010) Distinct functions of acj6 splice forms in odor receptor gene choice. J Neurosci 30:5028-5036.

Bai L, Goldman AL, Carlson JR (2009) Positive and negative regulation of odor receptor gene choice in Drosophila by acj6. J Neurosci 29:12940-12947.

Basbaum AI, Bautista DM, Scherrer G, Julius D (2009) Cellular and molecular mechanisms of pain. Cell 139:267-284.

Bourane S, Garces A, Venteo S, Pattyn A, Hubert T, Fichard A, Puech S, Boukhaddaoui H, Baudet C, Takahashi S, Valmier J, Carroll P (2009) Low-threshold mechanoreceptor subtypes selectively express MafA and are specified by Ret signaling. Neuron 64:857-870.

Brumovsky P, Villar MJ, Hökfelt T (2006) Tyrosine hydroxylase is expressed in a subpopulation of small dorsal root ganglion neurons in the adult mouse. Exp Neurol 200:153-165

Cavanaugh DJ, Lee H, Lo L, Shields SD, Zylka MJ, Basbaum AI, Anderson DJ (2009) Distinct subsets of unmyelinated primary sensory fibers mediate behavioral responses to noxious thermal and mechanical stimuli. Proc Natl Acad Sci U S A 106:9075-9080.

Cronk KM, Wilkinson GA, Grimes R, Wheeler EF, Jhaveri S, Fundin BT, Silos-Santiago I, Tessarollo L, Reichardt LF, Rice FL (2002) Diverse dependencies of developing Merkel innervation on the trkA and both fulllength and truncated isoforms of trkC. Development 129:3739-3750.

Dacey DM, Peterson BB, Robinson FR, Gamlin PD (2003) Fireworks in the primate retina: in vitro photodynamics reveals diverse LGN-projecting ganglion cell types. Neuron 37:15-27.

Duggan A, Ma C, Chalfie M (1998) Regulation of touch receptor differentiation by the Caenorhabditis elegans mec- 3 and unc- 86 genes. Development 125:4107-4119.

Dussor G, Zylka MJ, Anderson DJ, McCleskey EW (2008) Cutaneous sensory neurons expressing the Mrgprd receptor sense extracellular ATP and are putative nociceptors. J Neurophysiol 99:1581-1589.

Dykes IM, Lanier J, Eng SR, Turner EE (2010) Brn3a regulates neuronal subtype specification in the trigeminal ganglion by promoting Runx expression during sensory differentiation. Neural Dev 5:3.

Eng SR, Gratwick K, Rhee JM, Fedtsova N, Gan L, Turner EE (2001) Defects in sensory axon growth precede neuronal death in Brn3a-deficient mice. J Neurosci 21:541-549.

Eng SR, Lanier J, Fedtsova N, Turner EE (2004) Coordinated regulation of gene expression by Brn3a in developing sensory ganglia. Development 131:3859-3870.

Eng SR, Dykes IM, Lanier J, Fedtsova N, Turner EE (2007) POU-domain factor Brn3a regulates both distinct and common programs of gene expression in the spinal and trigeminal sensory ganglia. Neural Dev 2:3.

Erkman L, Yates PA, McLaughlin T, McEvilly RJ, Whisenhunt T, O'Connell SM, Krones AI, Kirby MA, Rapaport DH, Bermingham JR, O'Leary DD, Rosenfeld MG (2000) A POU domain transcription factor-dependent program regulates axon pathfinding in the vertebrate visual system. Neuron 28:779-792.

Fundin BT, Arvidsson J, Aldskogius H, Johansson O, Rice SN, Rice FL (1997a) Comprehensive immunofluorescence and lectin binding analysis of intervibrissal fur innervation in the mystacial pad of the rat. J Comp Neurol 385:185-206.

Fundin BT, Silos-Santiago I, Ernfors P, Fagan AM, Aldskogius H, DeChiara TM, Phillips HS, Barbacid M, Yancopoulos GD, Rice FL (1997b) Differential dependency of cutaneous mechanoreceptors on neurotrophins, trk receptors, and P75 LNGFR. Dev Biol 190:94-116.

Gan L, Xiang M, Zhou L, Wagner DS, Klein WH, Nathans J (1996) POU domain factor Brn-3b is required for the development of a large set of retinal ganglion cells. Proc Natl Acad Sci U S A 93:3920-3925.

Güler AD, Ecker JL, Lall GS, Haq S, Altimus CM, Liao HW, Barnard AR, Cahill H, Badea TC, Zhao H, Hankins MW, Berson DM, Lucas RJ, Yau 
KW, Hattar S (2008) Melanopsin cells are the principal conduits for rod-cone input to non-image-forming vision. Nature 453:102-105.

Hayashi S, Lewis P, Pevny L, McMahon AP (2002) Efficient gene modulation in mouse epiblast using a Sox 2 Cre transgenic mouse strain. Gene Expr Patterns 2:93-97.

Huang EJ, Zang K, Schmidt A, Saulys A, Xiang M, Reichardt LF (1999) POU domain factor Brn-3a controls the differentiation and survival of trigeminal neurons by regulating Trk receptor expression. Development 126:2869-2882.

Huang EJ, Liu W, Fritzsch B, Bianchi LM, Reichardt LF, Xiang M (2001) Brn3a is a transcriptional regulator of soma size, target field innervation and axon pathfinding of inner ear sensory neurons. Development 128:2421-2432.

Ichikawa H, Yamaai T, Jacobowitz DM, Mo Z, Xiang M, Sugimoto T (2002) Effect of Brn-3a deficiency on parvalbumin-, calbindin D-28k-, calretinin- and calcitonin gene-related peptide-immunoreactive primary sensory neurons in the trigeminal ganglion. Neuroscience 113:537-546.

Ichikawa H, Mo Z, Xiang M, Sugimoto T (2004) Effect of Brn-3a deficiency on parvalbumin-immunoreactive primary sensory neurons in the dorsal root ganglion. Brain Res Dev Brain Res 150:41-45.

Ichikawa H, Schulz S, Höllt V, Mo Z, Xiang M, Sugimoto T (2005) Effect of Brn-3a deficiency on primary nociceptors in the trigeminal ganglion. Neurosci Res 51:445-451.

Inoue K, Shiga T, Ito Y (2008) Runx transcription factors in neuronal development. Neural Dev 3:20.

Komiyama T, Carlson JR, Luo L (2004) Olfactory receptor neuron axon targeting: intrinsic transcriptional control and hierarchical interactions. Nat Neurosci 7:819-825.

Lanier J, Dykes IM, Nissen S, Eng SR, Turner EE (2009) Brn3a regulates the transition from neurogenesis to terminal differentiation and represses non-neural gene expression in the trigeminal ganglion. Dev Dyn 238:3065-3079.

Liu Q, Vrontou S, Rice FL, Zylka MJ, Dong X, Anderson DJ (2007) Molecular genetic visualization of a rare subset of unmyelinated sensory neurons that may detect gentle touch. Nat Neurosci 10:946-948.

Liu Q, Tang Z, Surdenikova L, Kim S, Patel KN, Kim A, Ru F, Guan Y, Weng HJ, Geng Y, Undem BJ, Kollarik M, Chen ZF, Anderson DJ, Dong X (2009) Sensory neuron-specific GPCR Mrgprs are itch receptors mediating chloroquine-induced pruritus. Cell 139:1353-1365.

Lumpkin EA, Caterina MJ (2007) Mechanisms of sensory transduction in the skin. Nature 445:858-865.

Luo W, Enomoto H, Rice FL, Milbrandt J, Ginty DD (2009) Molecular identification of rapidly adapting mechanoreceptors and their developmental dependence on ret signaling. Neuron 64:841-856.

Ma L, Lei L, Eng SR, Turner E, Parada LF (2003) Brn3a regulation of TrkA/ NGF receptor expression in developing sensory neurons. Development 130:3525-3534

Marmigère F, Ernfors P (2007) Specification and connectivity of neuronal subtypes in the sensory lineage. Nat Rev Neurosci 8:114-127.

Marquardt T, Ashery-Padan R, Andrejewski N, Scardigli R, Guillemot F, Gruss P (2001) Pax6 is required for the multipotent state of retinal progenitor cells. Cell 105:43-55.

Masland RH (2001) The fundamental plan of the retina. Nat Neurosci 4:877-886.

McEvilly RJ, Erkman L, Luo L, Sawchenko PE, Ryan AF, Rosenfeld MG (1996) Requirement for Brn-3.0 in differentiation and survival of sensory and motor neurons. Nature 384:574-577.

Mu X, Beremand PD, Zhao S, Pershad R, Sun H, Scarpa A, Liang S, Thomas TL, Klein WH (2004) Discrete gene sets depend on POU domain transcription factor Brn3b/Brn-3.2/POU4f2 for their expression in the mouse embryonic retina. Development 131:1197-1210.
Neumann S, Braz JM, Skinner K, Llewellyn-Smith IJ, Basbaum AI (2008) Innocuous, not noxious, input activates $\mathrm{PKC} \gamma$ interneurons of the spinal dorsal horn via myelinated afferent fibers. J Neurosci 28:7936-7944.

Pan L, Yang Z, Feng L, Gan L (2005) Functional equivalence of Brn3 POUdomain transcription factors in mouse retinal neurogenesis. Development 132:703-712.

Proske U, Gandevia SC (2009) The kinaesthetic senses. J Physiol 587:4139-4146.

Rau KK, McIlwrath SL, Wang H, Lawson JJ, Jankowski MP, Zylka MJ, Anderson DJ, Koerber HR (2009) Mrgprd enhances excitability in specific populations of cutaneous murine polymodal nociceptors. J Neurosci 29:8612-8619.

Rotolo T, Smallwood PM, Williams J, Nathans J (2008) Geneticallydirected, celltype-specific sparse labeling for the analysis of neuronal morphology. PLoS One 3:e4099.

Sanderson Nydahl K, Skinner K, Julius D, Basbaum AI (2004) Colocalization of endomorphin-2 and substance $\mathrm{P}$ in primary afferent nociceptors and effects of injury: a light and electron microscopic study in the rat. Eur J Neurosci 19:1789-1799.

Sedý J, Szeder V, Walro JM, Ren ZG, Nanka O, Tessarollo L, Sieber-Blum M, Grim M, Kucera J (2004) Pacinian corpuscle development involves multiple Trk signaling pathways. Dev Dyn 231:551-563.

Sun Y, Dykes IM, Liang X, Eng SR, Evans SM, Turner EE (2008) A central role for Islet 1 in sensory neuron development linking sensory and spinal gene regulatory programs. Nat Neurosci 11:1283-1293.

Sze JY, Ruvkun G (2003) Activity of the Caenorhabditis elegans UNC-86 POU transcription factor modulates olfactory sensitivity. Proc Natl Acad Sci U S A 100:9560-9565.

Tominaga M, Caterina MJ, Malmberg AB, Rosen TA, Gilbert H, Skinner K, Raumann BE, Basbaum AI, Julius D (1998) The cloned capsaicin receptor integrates multiple pain-producing stimuli. Neuron 21:531-543.

Trieu M, Ma A, Eng SR, Fedtsova N, Turner EE (2003) Direct autoregulation and gene dosage compensation by POU-domain transcription factor Brn3a. Development 130:111-121.

Wang SW, Mu X, Bowers WJ, Kim DS, Plas DJ, Crair MC, Federoff HJ, Gan L, Klein WH (2002) Brn3b/Brn3c double knockout mice reveal an unsuspected role for Brn3c in retinal ganglion cell axon outgrowth. Development 129:467-477.

Woodbury CJ, Koerber HR (2007) Central and peripheral anatomy of slowly adapting type I low-threshold mechanoreceptors innervating trunk skin of neonatal mice. J Comp Neurol 505:547-561.

Woodbury CJ, Ritter AM, Koerber HR (2001) Central anatomy of individual rapidly adapting low-threshold mechanoreceptors innervating the "hairy" skin of newborn mice: early maturation of hair follicle afferents. J Comp Neurol 436:304-323.

Xiang M (1998) Requirement for Brn-3b in early differentiation of postmitotic retinal ganglion cell precursors. Dev Biol 197:155-169.

Xiang M, Zhou L, Macke JP, Yoshioka T, Hendry SH, Eddy RL, Shows TB, Nathans J (1995) The Brn-3 family of POU-domain factors: primary structure, binding specificity, and expression in subsets of retinal ganglion cells and somatosensory neurons. J Neurosci 15:4762-4785.

Xiang M, Gan L, Zhou L, Klein WH, Nathans J (1996) Targeted deletion of the mouse POU domain gene Brn-3a causes selective loss of neurons in the brainstem and trigeminal ganglion, uncoordinated limb movement, and impaired suckling. Proc Natl Acad Sci U S A 93:11950-11955.

Xiang M, Gan L, Li D, Chen ZY, Zhou L, O'Malley BW Jr, Klein W, Nathans J (1997) Essential role of POU-domain factor Brn-3c in auditory and vestibular hair cell development. Proc Natl Acad Sci U S A 94:9445-9450.

Zylka MJ, Rice FL, Anderson DJ (2005) Topographically distinct epidermal nociceptive circuits revealed by axonal tracers targeted to Mrgprd. Neuron 45:17-25. 